\title{
Modeling of photovoltaic power generation and electric vehicles charging on city-scale: A review
}

\author{
Mahmoud Shepero $^{\mathrm{a}, *}$, Joakim Munkhammar ${ }^{\mathrm{a}}$, Joakim Widén ${ }^{\mathrm{a}}$, Justin D. K. Bishop ${ }^{\mathrm{b}, \mathrm{c}}$, Tobias Boström ${ }^{\mathrm{d}}$ \\ ${ }^{a}$ Department of Engineering Sciences, Uppsala University, P.O. Box 534, SE-751 21 Uppsala, Sweden \\ ${ }^{b}$ Energy Efficient Cities Initiative, University of Cambridge, Department of Engineering, Trumpington Street, Cambridge \\ CB2 1PZ, United Kingdom \\ ${ }^{c}$ Centre for Sustainable Road Freight, University of Cambridge, Department of Engineering, Trumpington Street, Cambridge \\ CB2 1PZ, United Kingdom \\ ${ }^{d}$ Energy and Climate Group, Department of Physics and Technology, UiT The Arctic University of Norway, NO-9037 \\ Tromsø, Norway
}

\begin{abstract}
Photovoltaics (PV) and electric vehicles (EVs) are promising technologies for increasing energy efficiency and the share of renewable energy sources in power and transport systems. As regards the deployment, use and system integration of these technologies, spatio-temporal modeling of PV power production and EV charging is of importance for several purposes such as urban planning and power grid design and operation. There is an abundance of studies and reviews on modeling of PV power production and EV charging available in the literature. However, there is a lack of studies that review the opportunities for combined modeling of the power consumption and production associated with these technologies. This paper aims to fill this research gap by presenting a review of previous research regarding modeling of spatio-temporal PV power production and charging load of EVs. The paper provides a summary of previous work in both fields and the combination of the fields. Finally, research gaps that need to be further explored are identified.

This survey revealed some research gaps that need to be further addressed. Improving the accuracy of PV power production ramp-rate modeling in addition to quantifying the aggregate clear-sky index on cityscale are two priorities for the PV potential studies. For the EV charging load models, differences in model assumptions, such as charging locations, charging powers and charging profiles, need to be studied more extensively. Moreover, there is an imminent need for metering the load of charging stations. This is essential in developing accurate models and time series forecasting techniques. For studies exploring both the PV and EV impacts, local weak points in a spatial network need to be discovered, especially for the city-scale studies. Cooperation between eminent researchers in the PV and EV fields might propagate state-of-the-art models from the separate fields to the combined studies.
\end{abstract}

Keywords: Photovoltaics power production models, Electric vehiclecharging models.

\section{Contents}

\section{Introduction}

2 City-scale modeling of PV power generation 4

2.1 Spatio-temporal solar irradiance modeling . . . . . . . . . . . . . . . . . . 4

2.2 Modeling of available building areas and PV systems . . . . . . . . . . . . . . 5

\footnotetext{
* Corresponding author

Email addresses: mahmoud.shepero@angstrom.uu.se (Mahmoud Shepero), joakim.munkhammar@angstrom.uu.se (Joakim Munkhammar), joakim.widen@angstrom.uu.se (Joakim Widén), jdkb2@cam.ac.uk (Justin D. K. Bishop), tobias.bostrom@uit.no (Tobias Boström)
} 


\section{List of Abbreviations}

$B E V$ Battery electric vehicle.

$B O S$ Balance of system.

$C C$ Constant current.

CHP Combined heat power plant.

$C V \quad$ Constant voltage.

$D O D$ Depth of discharge.

$D S O$ Distribution system operator.

$E V \quad$ Electric vehicle.

EVI Electric vehicles initiative.

GHG Green house gases.

GIS Geographical information system.

$H E V$ Hybrid electric vehicle.
$H P$ Heat pump.

$I C E V$ Internal combustion engine vehicle.

IEA International Energy Agency.

LiDAR Light detection and ranging.

NREL National Renewable Energy Laboratory.

PHEV Plug-in hybrid electric vehicle.

$P V \quad$ Photovoltaics.

$R M S E$ Root mean square error.

$S O C$ State of charge.

TOU Time of use.

$V 2 G$ Vehicle to grid.

3 Modeling of EV charging load

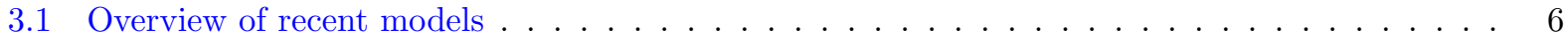

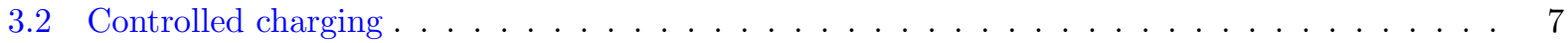

$4 \quad \mathrm{PV}$ and EV synergies

5 Concluding discussion

\section{Introduction}

Since electricity generation and transportation accounted for $60 \%$ of all energy use in the world in 2013, renewable energy sources for electricity generation and electrification of transport provide a great potential for reducing fossil fuel use [1,2]. In an ambitious set of targets the European Commission has setup a 5 policy framework for 2030 which includes $40 \%$ reduced $\mathrm{CO}_{2}$ emissions compared with the 1990 level [3]. This implies reducing energy use, increasing energy efficiency and increasing the percentage of energy demand met by renewable energy sources.

While electrification of transport presents a great possibility for reducing $\mathrm{CO}_{2}$ emissions [4], a renewable energy source of the electrification, such as photovoltaics (PV) power production, presents an even stronger case [5]. This, however, is contingent on the use of plug-in vehicles. The number of electric or hybrid vehicles has risen rapidly in the world, with over 565,000 plug-in cars sold globally 2011-2015 [6]. In the year 2016, the global sales of plug-in cars exceeded 750,000 vehicles [7]. Electric vehicles (EVs) is a term applied to hybrid electric vehicles (HEVs), plug-in hybrid electric vehicles (PHEVs), and battery electric vehicles (BEVs) [8]. In this paper, EVs refer only to PHEVs and BEVs.

As an example, a target of 20 million EVs and fuel cell vehicles, on the road was set by the Electric vehicle initiative (EVI) to be achieved in 2020 [9]. This target is expected to be surpassed if the $78 \%$ growth rate achieved in the year 2015 was maintained [10]. However in the year 2016, the annual growth rate of EV sales has fallen below $50 \%$ for the first time since 2010, and the annual growth rate of publicly available charging has increased by $72 \%$ [11]. The Electric and plug-in hybrid roadmap aims that EVs represent 50\% of the sales of vehicles worldwide by 2050 [12]. This is to say that the current research is investigating penetration levels of EVs that are expected to take place within decades, which is likely going to affect the 
household electricity consumption patterns. This change will make the current studies inaccurate in their representation of the grid load. Thus, continuous updating of modeling parameters is needed to cope with changing external factors.

Alongside the electrification of transport, the share of renewable energy has risen as well. In particular PV power capacity grew by 50 percent — or 75 GW — during 2016 [13, p.4], and a cumulative $303 \mathrm{GW}$ was installed globally as of 2016 [13, p.7]. The growth of PV power production in the world is mainly due to falling prices on PV panels, balance of system (BOS), and installation costs, largely due to increases in production volume, and governmental subsidies $[14,15]$. The price for PV systems have been more than 30 halved from 2007-2015 [15]. However, in mature markets the PV power production installation rate rapidly decreased and the total installed capacity appears to stagnate below 10 percent of the installed electricity generation capacity [14, p.15]. Still, for these capacities, PV power production has potentially adverse effects on the local electricity grid, such as over-voltage and even component failure [16]. For these situations local self-consumption of PV power can reduce the risk of adverse effects by reducing the electricity that is fed into the grid. In this case there is potential for using PV power to charge EVs [2, 17-20].

Type of EV charging, as well as location and time of charging affects the synergy potential of combining $\mathrm{PV}$ power production and EV charging, where controlled charging generally has higher potential than uncontrolled charging [18]. Uncontrolled charging is here defined as opportunistic, as opposed to controlled charging, which can be based on some scheme. Estimates of opportunistic EV home-charging suggest that 40 home-charging occurs mostly during late evening (from about 6 p.m.) and night-time [17, 21]. When combined with PV power production that is an increased self-consumption [17], but that it generates a larger mismatch overall [5, 17]. It should also be emphasized that the match between PV power production and EV charging is higher when aggregates of charging stations and PV power systems are considered [22]. It should also be mentioned that local battery storage can also improve this matching [23].

Multiple businesses in the electricity sector - like grid operators, power plants, electricity traders, and large consumers - rely heavily on accurate load models [24-27]. Even for city planning purposes and for design and operation of urban electricity distribution grids, models of future dispersed PV power production and EV charging patterns are important for, e.g., matching variability in PV supply and improving local self-consumption of PV production in EV charging [2, 16, 28-30]. Models that combine a realistic spatial distribution over a city or parts of a city with high time resolution are necessary for detailed system integration studies. However, there is a lack of data for EV charging on the city-scale [31], and the literature is even more scarce on the combination of EV charging and PV power production in cities. At the same time, recent research on solar irradiance has provided advances in modeling of dispersed and correlated high-resolution irradiance over small spatial scales, and there is an abundance of EV models that address different important aspects, including time-scales and driving patterns [2, 32]. There should be opportunities for a combined modeling approach based on existing models. A first step towards this is to map the current state-of-the-art in the PV and EV modeling fields.

The aim of this review paper is therefore to provide an overview of the fields of EV charging and PV power production modeling on city-scales to identify the main research and development gaps and the 60 opportunities for combining modeling approaches for the two technologies. The paper provides a summary of previous work in both fields and the combination of the fields — which was not performed as extensively before - and identifies gaps that need to be further explored in future research. Reviewing time series forecasting techniques is beyond the scope of this paper because of the following reasons: (1) time series forecasting techniques for PV power production were reviewed before in [33, 34], and (2) EV charging load

65 forecasting papers are scarce. This is a result of the scarcity of metered data measured at charging stations [31, 35]. Among Ref. [35-37] who developed forecasting techniques for EV charging load, only [36] used recorded load data. Ref. [35, 37] relied solely on exogenous variables - such as ambient temperature, traffic data, and driving behaviors - in their forecasting technique.

The authors read and analyzed previous research contributions in addition to the important former 70 advancements in both fields individually and combined. The aim is to highlight the previous research results along with the currently unanswered questions so that forthcoming studies explore the open questions and avert the formerly explored ones.

The paper is structured as follows. Section 2 reviews recent advances in solar irradiance and PV power 
production modeling that allow city-scale spatio-temporal models of dispersed PV systems to be developed. 75 Section 3 reviews EV charging models, with a broad overview of available models and a special focus on controlled charging, which is generally believed to be necessary for a smooth integration into the existing infrastructure. Section 4 reviews the existing studies and models of combined EV charging and PV power production. Finally a concluding discussion, pointing out gaps in knowledge, data and model capabilities, is given in Section 5 .

\section{City-scale modeling of PV power generation}

For modeling the power output from a large number of PV systems spatially distributed over time in a city, three main parts need to be included: (1) the solar irradiance distributed over the systems, taking varying cloudiness into account, (2) a method for identifying and efficiently representing a large number of building areas on which PV systems are mounted, and (3) suitable models for conversion of irradiance 85 components between horizontal and tilted planes and for PV system output. In the following sections we summarize current state-of-the-art and common practice in these areas.

This section contains spatio-temporal modeling of solar irradiance, and excludes forecasting, since that is outside the scope of this paper. For overviews of solar irradiance and solar power forecasting, see, e.g., Ref. [33, 34].

\subsection{Spatio-temporal solar irradiance modeling}

Broadly speaking, a spatio-temporal model of solar irradiance describes how the irradiance simultaneously varies over both space and time. The output is typically irradiance time series [38], probability distributions for instantaneous irradiance [39] or some measure of variability [38] for a number of dispersed sites [38] or aggregated over a geographical area [40,41]. Input data are typically meteorological parameters that

95 characterize the weather at a certain location, either very generalized, such as the daily clear-sky index [39], or more detailed cloud cover parameters [39].

As many studies over the last years have shown, temporal variability of the solar irradiance over a set of sites can be considerably smoother than at a point location, with higher dispersion leading to lower total variability (for overviews, see e.g. Ref. [42, 43]). This is because cloudiness varies over dispersed sites, making high-resolution irradiance time series measured at different sites more or less correlated or uncorrelated depending on the distance between them. Knowledge about this distance-smoothing effect stems both from dense solar radiation networks [44-48] and from monitored PV plants [49-52] and is similar in character to that of other weather-dependent renewables, such as wind and wave power [43]. Common practice for solar irradiance is to study and model the clear-sky index, which is the ratio between global solar radiation and the corresponding clear-sky radiation, and essentially describes the non-systematic variability (cloudiness variability) in the solar irradiance.

Spatio-temporal irradiance models are often built around a correlation model. This is the case for the so-called wavelet variability model [41], in which a single-site time series is smoothed out to represent the profile of a set of distributed sites or a large PV plant. A correlation model also makes up the backbone of a recent analytical model for the irradiance variability continuously distributed over an area [53] and in several solar forecasting approaches [54-56]. Correlations between sites in terms of solar irradiance over short distances and high time resolutions were first studied and modeled in Ref. [47, 57-59]. Exponential decay models are the ones most commonly used to describe how the correlations depend on the distance between sites [42,60], although there are indications that logarithmic modeling could be more accurate [53].

An important distinction to make is between isotropic and anisotropic correlation models. In the former, the correlation is assumed to be independent of the direction of cloud movement, while in the latter it depends on the cloud or wind direction. For ramp-rate correlations, empirical measurements have shown that the correlations are highly anisotropic for along-wind station pairs and cross-wind station pairs [48]. Anisotropic correlation models have subsequently been proposed [61,62] and should be preferred for realistic spatio-temporal models.

A promising way to describe spatially distributed high-resolution solar irradiance is through probabilistic modeling. Early investigations of the clear-sky index at individual sites showed that it was bimodal or, at 
least, that it displayed asymmetry with respect to the mean value [63-71]. Characterizations of probability distributions have since improved from daily and hourly resolution [72-75] to minutely or near-instantaneous resolution [76-79], and probability distribution models have been developed for characterizing the clear-sky index. Examples of distribution families for representing the clear-sky index include single Gamma [74], single Boltzmann [73], Bi-exponential [80], double Normal [78, 81], double Beta [82], double Boltzmann [79], Logistic combined with Weibull [83] and recently triple Normal [84]. Also a convolution-type model has been developed [85]. No clear preference for a single distribution family is indicated by the literature, which motivates further comparative studies.

Spatially correlated probability distributions can be modeled via a joint distribution function called a copula [86]. This methodology has been used for modeling of dispersed wind power plants [87], but has a yet largely unrealized potential of contributing to spatio-temporal solar irradiance modeling. Initial studies on using copula to model solar irradiance suggest that it can be used on city-scale [88], and possibly even regional scale, at least if applied to PV power generation [89].

\subsection{Modeling of available building areas and PV systems}

To go from spatially modeled clear-sky index to a full model of distributed PV systems within a city a number of steps are typically involved. First, to model sites for building-applied PV systems we must be able to identify available building areas. Second, clear-sky index data at these sites need to be converted to solar irradiance, for which a clear-sky irradiance model is required. Third, we must be able to convert solar irradiance on the horizontal plane to the tilted plane of the building-applied PV system. Finally, a PV model must be used to convert in-plane solar irradiance to PV power output. State-of-the art modeling within each of these steps is summarized below.

Methods for assessing areas available on buildings for PV systems were reviewed in Ref. [90], which divided methods into constant-value methods (using high-level statistics to make rough estimates in regions), manual selection methods (based on manual identification of rooftops from aerial photographs) and geographical information system (GIS)-based methods (applying algorithms to GIS-based building data for automatic detection of suitable areas). For spatio-temporal PV system modeling on city-scale, the last set of methods is clearly the most relevant. Most existing studies using the latter method have been used for determining the annual energy potential [91, 92], but there have been attempts at GIS-based spatio-temporal modeling with higher temporal resolution [93]. For studies of widespread PV dispersion in cities, there are recently developed methods that automatically construct low-complexity polygon models of buildings from light detection and ranging (LiDAR)-data [94-96].

For determining global radiation on building surfaces from clear-sky index data, several detailed and advanced clear-sky models are available. Models that estimate the solar irradiance in cloud-free skies for any time and location on Earth exist, such as the state-of-the-art models McClear [97] (for a thorough review see [98]) and National Renewable Energy Laboratory's (NREL's) Bird Clear-Sky Model [99]. These are fully physical models, including advanced atmospheric and radiative transfer models. For a survey of different models and model types see [100]. In general, the error of simpler models tends to vary over time more than that of more advanced models, even though the simpler models are only slightly less accurate than the more advanced ones given the same conditions [101]. Among the models compared in Ref. [101], the most accurate model, which was an advanced model, achieved a root mean square error (RMSE) of $4.7 \%$ while one of the simpler models achieved a RMSE of $6.3 \%$.

For converting incident solar irradiance from the horizontal plane to the tilted plane, both the diffuse and beam components must be available. Since only global irradiance can be obtained by combining global clear sky irradiance with the clear-sky index, global radiation must first be split into beam and diffuse radiation. Several methods are available for this [102], with the Erbs model being commonly used due to its simplicity combined with a good performance [103]. Different models also exist for converting diffuse radiation to the tilted plane $[104,105]$. Two of the most commonly used ones, both with good performance, are the Hay model [106] and the Perez model [107].

The last step in city-scale PV modeling is the model of the PV systems. Several PV performance models are available [108], with varying degrees of complexity. For city-scale modeling, it is reasonable to aim for 
a less complex model which still reproduces the essential features of PV modules, such as [109, 110], and a reasonably simplified model of inverters, such as in [111].

The most common type of PV installation is grid-connected [15], which constitutes distributed generation of PV power production in the electricity distribution grid [16]. There are two main challenges with intermittent distributed generation: on the one hand, there is an increased need for power system balancing to keep the system frequency within limits; and on the other, the local distribution grid may experience new, reversed, power flows, voltage rise and component overloading [16]. Several studies explored PV impacts on the electricity grid [112-116]. Ref. [117] studied the approaches followed by several countries aiming to improve PV integration in the grid. The challenge for distributed generation thus regards the limits of the distribution grid. The term, 'hosting capacity' can be used to define the amount of distributed generation power for which the grid performance becomes unacceptable [118]. There are a number of possible ways to increase the hosting capacity though such as altering tap changer settings, curtailment, reactive power control and self-consumption [23, 118].

\section{Modeling of EV charging load}

The current research on EVs charging is based on the outcomes of the research in the previous century. Since 1913 benefits of off-peak charging have been perceived [119]. These benefits were further explored in Ref. [120]. Some models were based on mechanical estimation of the specific consumption $(\mathrm{kWh} / \mathrm{km})$ of the EVs [121] based on data including vehicle dynamics and the driving cycles of the drivers. Vehicle dynamics data contains data about aerodynamic drag, weight, and drivetrain efficiency of the vehicle. Driving cycle is the pattern according to which speed changes with time. The previous models were implemented on HEVs that cannot be connected to the grid. However, a recent model in 2011 followed the same approach on EVs [122]. In the year 1999, Ref. [123] developed a probabilistic model to estimate the charging load of 10000 EVs in an urban area. The daily driving distance as well as the charging start time were probabilistically distributed. Nowadays, probabilistic models are more often used to represent trip start and end times as well as daily driving distance distribution. Ref. [124] developed a deterministic model that estimated the charging load of EVs, the model used average driving distance as well as the specific consumption to estimate the impact of night time and fast charging on the grid. The impacts of EVs charging on the electricity grid were studied in Ref. [125, 126]. Controlled charging was explored in Ref. [127, 128].

\subsection{Overview of recent models}

Nowadays, accurate EVs charging models are essential tools to predict the impacts of EVs on the electricity grid. The mathematical models developed in the literature are plentiful. They can be categorized based on their modeling technique to Markov chain models [21, 129, 130], queuing theory models [131-133], deterministic models [134], Bayesian inference model [135], Markov-modulated Poisson process [136], zero inflated Poisson [137], joint searching scheduling algorithm [138], fuzzy based model [139], Gaussian mixture model [140], and other stochastic models [141, 142]; or based on the simulation techniques to Monte Carlo [129, 135, 142-144], and fuzzy linear programing [145]; or based on the probability distribution to Poisson distribution [138, 144], Gaussian distribution [129, 142]. Overall, the accuracy of the model is not dependent on the modeling technique, rather it depends on the model assumptions. In general, stochastic models tend to cater for uncertainties of the charging vehicles. Hence, stochastic models tend to provide better security risk assessment for the system at hand $[141,142]$. On the other hand, deterministic models tend to represent the worst case scenario in the grid [142].

Models can be also categorized depending on the input data of the model. The most basic models rely on measuring the charging load of a number of EVs, then this data is used to generate the demand profile of a large number of EVs as in Ref. [137, 146, 147]. Alternatively, the models presented in Ref. [129, 138, 146-154] relied on statistical data for vehicles driving in cities. In most of the cases, the statistical data was data for internal combustion engine vehicles (ICEVs) due to the abundance of statistics on this type of vehicles in comparison with the EVs. It is often assumed that the driving habits of EV owners will 
measure charging data from EV charging stations $[133,139,142,144,156]$. These models are not as wide spread as the previous ones due to the scarcity of charging stations in general. Moreover, few existing stations record data from charging sessions [31, 35]. Combining data from charging stations and driving statistics will result in a more accurate model. Data from driving statistics will calibrate the total daily charging needs of the vehicle, while data from public charging stations will calibrate tendency of vehicle owners to publicly charge their vehicles. This modeling strategy needs to be further implemented in the future studies, since the accessibility of public charging stations, which is an important step towards more sustainable transportation [157], is expected to significantly increase in the future. Consequently, owners of EVs will be able to charge their vehicles during the day in public charging stations and charge their vehicles at home in the evening.

With the expected increase in public charging stations, more models are expected to assume that the owners of EVs will have the ability to charge their vehicles in different locations during the day, for example at work and at home. In the literature, this assumption was studied in Ref. [129-131, 143, 146, 150]. Accurate predictions of the daily charging load in charging station is an important input to planning new charging the daily load of the charging station is paramount in the selection of the station equipment. It is also vital in the assessment of the capability of the grid to withstand the station's charging requirement. Models developed in Ref. [131, 141, 144, 156, 158] estimated the load of EV charging stations.

Most of the models in the literature assume a constant charging power during the whole charging session. This assumption is, however, not accurate [159]. On the other hand, constant power charging represents the worst case scenario for charging an EV. Batteries, however, have different charging stages, and charging power is not constant in the stages. Batteries are charged using various charging methods like: constant current (CC), constant voltage (CV), constant power, and taper charging [160]. The commonly applied method is a mixture of CC and CV charging [161]. As depicted in Figure 1, in this method the charging session starts with CC until a certain voltage is reached, after that the charger completes charging through (162]. Models developed in Ref. [137, 147, 159, 163] consider the dependence of charging power on the charging stages. The inaccuracy of assuming constant power charging on the modeling results has still not been explored.

Charging of EVs induce a stress on the electricity grid $[153,164,165]$. Since EVs consume large amounts of energy at high power, undesirable peaks can occur in the electrical system [165]. In the year 2014, the (IEA) member states recorded an average final electricity consumption of 21.85 $\mathrm{kWh} /$ day/capita [166] which is smaller than many EVs batteries. Several papers studied the effect of EVs charging on grid voltages $[141,142,144,147,153,164,165,167,168]$, power peaks $[142,144,149]$, network losses $[142,144,149,152,153,165,167]$, and components loading [141, 142, 144, 147, 151, 152, 164, 168]. Usually, studies that explore the impacts on the electricity grid propose a controlled charging strategy to reduce the impact on the grid $[142,151-153,164,169,170]$

Figure 1: The voltage and current variation during a charging session of a battery. In this diagram the CC-CV method is used for battery charging. This figure is inspired by Ref. [8, 159, 162].

\subsection{Controlled charging}

Regardless of model assumptions and grid topology, there is a consensus in the literature that uncontrolled charging of EVs stresses the electricity grid. Ref. [171] showed that the enhancements needed in the grid cost up to $19 \%$ of the network costs without EVs and $60-70 \%$ of these costs can be reduced through controlled charging. In order to alleviate this stress, controlled charging should be implemented. In addition to enhancement to the grid stability, controlled charging has other advantages, such as reducing charging costs for both EV owners and grid operators. Controlled charging is proposed in many research papers. However, the user acceptability of the controlled charging was not considered while modeling. The models assume that the users are going to adopt the controlled charging strategy precisely as designed which might not be the case. Based on a survey on $237 \mathrm{EV}$ owners, Ref. [172] showed that the respondents were motivated to adopt controlled charging when it protects the grid and when it improves the integration of renewable 
energy sources. Owners also showed little motivation towards monetary compensation. Besides that, they expressed an unwillingness towards sacrificing their flexible mobility for the sake of controlled charging.

Controlled charging strategies in the literature are divided into two categories: centralized and decentralized strategies. The decentralized strategies allow vehicle owners to schedule their charging. The centralized charging employs a controller that schedules the charging of multiple vehicles [173, 174]. The centralized controller can be placed in the charging station or, in some cases, can be a separate entity known as an aggregator. The controller is responsible for acquiring data about electricity prices, the grid situation as well as the state of charge (SOC) of the vehicles under control. The decentralized strategy can be easily scaled up to match the number of participating vehicles besides it is more tolerant to faults and requires less computational power and communication lines [173]. On the other hand, the centralized strategy ensures optimal charging of EVs and provides more services to the grid operator and the electricity market [174]. The business model of aggregators requires a large number of vehicles that can be controlled otherwise the model will not achieve the aimed outcomes [175]. Hence, high penetration of EVs is a prerequisite for an aggregator scale controlled charging. Table 1 provides an overview of the controlled charging strategies in the literature.

Table 1: Summary of literature investigating controlled charging.

\section{PV and EV synergies}

The environmental impact of driving an EV is highly dependent on the primary energy source of the electricity grid used to charge the vehicle [176, 177], this dependence is decreasing as emission control in power plants is improving [176]. On the other hand, half of the life cycle environmental impact of EVs occurs during production [178]. For example, in the USA and China, an EV that is charged using $80 \%$ electricity from renewable energy sources could reduce green house gases (GHG) emissions by up to $85 \%$ compared with the current emissions [176]. EVs can emit more $\mathrm{CO}_{2}$ and $\mathrm{SO}_{2}$ compared with ICEVs in electricity grids that rely on a coal-natural gas mixture as the primary energy source [179]. Consequently, synergies between renewable energy sources like PV and EVs are paramount to increase sustainability in transportation [180]. A study made on the EU countries showed that the major benefits of switching from ICEVs to EVs is the reduction in local emissions [181]. Moreover, EVs are more efficient and dissipate less heat compared with ICEVs. As a result, the energy consumption for air conditioning in cities was reduced by 14.4 million $\mathrm{kWh}[182]$.

Charging EVs during both daytime and night-time increases the daily mileage driven by the same battery capacity compared with only night-time charging [18, 183, 184]. This finding demonstrates the possibility of reducing the EV battery size [18]. This scenario will only be feasible provided that owners have access to charging stations during the day. Moreover, increasing accessibility to charging stations is an important step towards more sustainable transportation [157]. Following Ref. [185], the literature studies exploring synergies between PV and EVs can be categorized based on the scale of the study into three categories: small, medium, and large scales. Small scale studies focus on the scale of parking lots and charging stations, while low voltage feeders and residential neighborhoods are studied in the medium scale studies. The large scale studies explore the synergies on the scale of a whole city. It is important to note that the scale of the study depended on the scale of the impact which the authors intended to investigate.

Ref. [29, 186-193] studied the energy balance between the local PV power generation and the EV charging load. Controlled charging benefits were explored in [18, 28, 194-197]. Grid optimization was studied in [198]. Financial and environmental benefits were explored in [193, 199]. Finally, several studies proposed operating strategies for smart charging stations that take into consideration the PV production and the electricity grid loading [200-208]. 
Solar panels installed above parking lots represent a great potential for charging EVs with the already available solar energy during the day. This locally produced energy will reduce the impact of EV midday charging on the electricity grid. The amount of impact reduction depends on the grid design, the penetration of the PV and EVs, the existence of battery storage systems and other model assumptions such as charging power. A study in New Jersey [186] estimated the yield from a horizontal PV panel installed above a parking lot of $15 \mathrm{~m}^{2}$. The results showed that the yield energy is enough to drive EV commuters to and from work given that they live within a radius of $24 \mathrm{~km}$ of their work. Another study in Switzerland [190] estimated the potentials of installing PV on parking lots. Only 29 stations out of the 40 studied were suitable for PV production. The annual energy produced was enough to supply $40 \%$ of the energy needed to drive light weight EVs. A similar study was made on three different locations in Italy [191]. This study simulated different charging scenarios as well as different initial SOCs for the batteries of the EVs. Energy from PV could supply from $1 \%-3 \%$ to $56 \%-72 \%$ of the needed energy to charge the EVs. In the Netherlands, a study [192] estimated the impacts of installing battery storage systems as well as PV on workplace charging station. The results proved that without having the battery storage installed PV can supply up to $60 \%$ of 作 imported from the grid by $25 \%$. However, the utilization of the battery is not proportional to the battery capacity, and since $75 \%$ of the variations in solar insolation between days is less than $15 \mathrm{kWh}$, batteries with capacity less than $15 \mathrm{kWh}$ were recommended by the authors. The authors in [199] studied the financial and environmental benefits form adopting a PV powered charging station for EVs compared with

330 home-charging. This study was made on two US universities, one located in Ohio and the other located in California. The payback period of the PV was dependent on the parking fee and the size of the panels. Nonetheless, it ranged between 4-30 years.

A recent similar study compared the economic and environmental impacts of a university-located EV charging station using different orientations of PV panels in Sicily [193]. The authors observed that the eastoriented panels resulted in a higher self-consumption. In the same time, east-facing panels reduced the daily solar production in the winter by up to $20 \%$. However, the south-oriented panels required energy storage to shift the afternoon solar production to the following day's early morning charging. The authors showed that orienting the PV panels to match the early morning charging — east orientation — will cost $77 \%$ of the south-directed panels and storage. This value was obtained when the authors oversized the east-oriented panels, compared with the south-oriented panels, to account for the $20 \%$ drop in daily production in the winter months. In Ref. [209], the authors developed an optimization algorithm to control the energy flow between a charging station connected to building where PV panels were installed on both the station and the building. The objective of the optimization was to minimize the operating cost. The authors studied combinations of different building types, different charging availability, and different initial SOC. Building types such as office, apartment, warehouse, etc. were included, and charging availability included daytime long duration, daytime short duration and night time charging. Unfortunately, the optimization algorithm did not adjust the orientation of the PV panels. The previous two papers revealed a research gap regarding the relation between the orientation of $\mathrm{PV}$ panels and the self-consumption of EVs for different charging behaviors like early morning and late afternoon charging.

In [194], the authors studied the possibility of controlling the voltage of a low voltage feeder that had high PV penetration level using an EV charging station that had a battery storage system. This study was performed on a 7 bus feeder supplying 33 residential customers with a $28 \%$ PV penetration level (measured as a percentage of total energy consumption). The results showed that EV charging stations can ensure that the feeder voltages remain within safe limits. Moreover, the capacity of the battery storage system decreased with the increase of the distance between the EV charging station and the transformer, $47 \mathrm{kWh}$ for the furthest location compared with $12 \mathrm{kWh}$ for the nearest location. Ref. [198] developed an optimization technique to optimally size and allocate solar parking lots for EVs located in a LV feeder. The objective of the technique was to reduce the costs and to ensure that the network is operating within safe limits. The technique reduced the energy loss in the grid by $49 \%$ and reduced the total costs by $39 \%$. The authors in [195] proposed a coordination scheme between combined heat power plants (CHPs), PV, battery storages and EVs in an industrial micro-grid. The results showed a reduction in the overall costs of the industrial micro-grid, a reduction in EV charging costs and an enhancement in network security. Another similar 
study was based in Belgium [210]; this study explored charging of EVs in an office building micro-grid that contained a CHP unit and PV. The percentage of self-consumption of the energy produced from the PV and the CHP increased with the increase in the number of EVs. The amount of increase varied based on the charging scenario, the charging power, and the number of EVs. The self-consumption increased up to $80.2 \%$ from $70 \%$ when no EVs were charged. The study also showed that controlled charging could reduce the impact on the grid. The conclusion is that workplace charging using PV will reduce the charging load on the grid. An extensive study [28] explored the implication of various levels of PV and EV penetration on a small

370 test feeder. The PV penetration ranged from no PV to each customer installing $25 \mathrm{~m}^{2}$ of PV panels, and the number of EVs varied from zero to one EV per household. Moreover, different EV charging strategies were simulated. Synergies between PV and EVs helped reduce the drawbacks of each. However, both technologies have opposite implications; consequently no ideal solution to all the problems was achieved. One limitation of the previous study arose from the fact that it tested a feeder with small impedances and short distances between nodes which may have affected the results of the simulation [211]. This indicates the necessity of further research in this area.

On the larger scale, Ref. [196] assessed the synergy between PV and EVs in a city in Northern Italy. Two modes of EV charging were modelled: controlled and uncontrolled charging. The controlled charging increased the maximum EV penetration by $64 \%$ compared with the uncontrolled charging. Moreover, the penetration level of PV increased from $218 \%$ to $249 \%$ when implementing controlled charging. Ref. [29] estimated the electricity demand profile of the city of Toyonaka in Japan in the year 2030. Various scenarios were proposed for EVs and PV penetration in the grid. This study revealed that PV reduced the total electricity load by $19.7 \%$ and using vehicle to grid (V2G) cut peaks by $37.3 \%$. The authors in [212] modeled actual households' consumption and PV data in an urban region in Brazil. The aim of the study was to use V2G to stabilize the network and achieve financial profit to the owners of the EVs. In this study, the feeder was able to handle all the energy generated from the PV panels. Financial profit up to $\$ 1000$ was possible with only $40 \%$ allowable depth of discharge (DOD) for the V2G to operate within. A study made on Kansai area in Japan [197], an area which has 8 million households and 7.76 million cars, integrated PV, EVs, and heat pumps (HPs) at various penetration levels. High levels of PV penetration could be achieved through charging EVs and operating HPs during off-peak hours and during high PV production. During peak hours, EVs could supply electricity to the grid and HPs could go on standby mode. In Texas, a study [18] performed on a grid supplying 23 million customers explored the benefits of combining both PV and EVs. The study assumed that EVs constitute $50 \%$ of the transportation sector. Two charging strategies were explored; controlled and uncontrolled. Uncontrolled charging assumed that the vehicle is charged whenever parked. Controlled charging was similar to the uncontrolled charging strategy but it stopped charging during peak hours form 3 p.m. to 9 p.m. provided that the vehicle would be fully charged at 7 a.m. The results showed that the synergy between PV and EVs reduced the demand peaks and decreased the curtailed PV energy during times of high solar production and low demand.

It was shown that the population density is inversely correlated with both the energy used for transportation and the solar production, both measured per capita [187-189]. This is to say that the solar yield from PV installed above a certain roof and the energy used for transport by the inhabitants who live under the same roof both decrease as the population density increases. A study made on the city of Toronto, Canada, explored the relationship between the energy use per capita and population density [187]. The study included the households' energy use, transportation energy use, and solar energy generation. The authors showed that the net yearly energy use per capita is lower in densely populated regions compared with the sparsely populated ones. They also showed that this trend was reversed if highly efficient solar panels in addition to strict-efficiency measures were adopted at homes which included shifting to EVs. In this study, the authors assumed that the roofs were horizontal. In addition, they also included the solar yield from facade mounted PV panels. In Ref. [188], the authors evaluated the solar rooftop potential in the city of San Francisco and compared this to the vehicle energy use. The authors compared the electricity produced by a certain rooftop and the electricity consumed by the vehicles owned by the people living under this roof, the results were compared in $\mathrm{kWh} /$ capita. The results showed that the yearly yield of the $\mathrm{PV}$ panels is higher than the charging load of the vehicles — both in $\mathrm{kWh} /$ capita — if BEVs replaced conventional ICEVs. This result was valid for all population densities. However, when spatially presented, 
few regions had a higher BEV charging load compared with PV production. Unfortunately, the authors did not comment on this finding. One limitation for this study was that they calculated the solar production of one fourth of the rooftop areas - including the north facing sections of tilted roofs. In [189], the authors calculated the energy generated from the potential PV installations on rooftops and facades of buildings in the city of Aukland in New Zealand. They included only the most efficient facades and roofs - above $95 \%$ - depending on the tilt and orientation of the PV panel. Unfortunately, they did not describe the methodology used to evaluate the efficiency of the roofs and facades. The authors showed that the persons share of PV production could accommodate for the EV charging load regardless of the population density. The previous three studies used deterministic assumptions for the EV models. The use of stochastic assumptions is preferred over deterministic assumptions [213].

\section{Concluding discussion}

The current rate of uptake of PV and EVs indicates that these technologies are going to have significant impacts on the electricity grid in the future. The impacts include both challenges, like increase in grid losses, and potentials, like balancing the intermittence of the generation and the load. A careful assessment of the impacts is paramount to ensure successful adoption of both technologies. In this paper, a review of the current research related to modeling the power use and production for both technologies has been presented. Even though the amount of research that was done on these topics is plentiful, there are some gaps that need to be explored.

First regarding PV power production modeling, improved modeling of variability of the clear-sky index over space and time is of interest. That is, improved accuracy for estimating PV power production ramprate can assist future smart grids more accurately match power supply with demand. Also, quantifying the aggregate clear-sky index and subsequent PV power production on a city-scale, is interesting. Here high resolution solar irradiance data on city-scale for various regions is scarce, and more metering networks such as NREL's radiometer array [214] at Oahu, Hawaii, USA, could be useful. Improved modeling of solar irradiance for single or multiple locations might also assist in improving the models for PV power production 440 forecasting.

As regards EV charging models, there is a need to introduce more variability in the model assumptions. That is, multiple charging powers, charging locations, and battery capacities need to be modeled in the same paper. This strategy will ensure a more accurate model that reflects the different requirements of different EVs. Moreover, there are few papers that model the charging spatially over a complete city. Spatial models 445 excel at predicting the impacts of charging in multiple locations in the grid and during different times of the day. Future research on V2G and controlled charging is expected to find a compromise between the needs of vehicles owners and grid stability. Further research needs to explore the impact of the high PV and EV penetration on the electricity tariffs and electricity market. Moreover, the reaction of vehicle owners to aggregator requirements needs to be further explored. Comparative studies that estimate the costs of grid enhancements compared with the costs of controlled charging need to be further explored. Also, more detailed data on EV charging could be beneficial for narrowing down the vast number of EV models and free parameters, potentially giving more accurate predictions.

Finally, as regards the combination of modeling PV power production and EV charging, there is a need for improved modeling on the variability of the combined power use and production in the local distribution grid. In particular, for various profiles of charging, such as home-charging, work charging and public charging. In similarity with the research gaps identified for both PV power production modeling and EV charging modeling, there is a gap in the understanding of the variability of the combination of this for large scales, such as city-scale. City-scale studies lag behind the former advancements reached in the separate fields. In other words, advanced spatial models for the solar yield and the charging load of EVs for the different profiles of charging are still missing. Collaborations between researchers in both fields are encouraged. The next step of that is to estimate electricity grid-impacts, and to identify the spots of critical power production or consumption in the grid, and to quantify the potential and need for controlled charging. 


\section{Acknowledgements}

This project was funded by the EU ERA-Net Smart Grids Plus project "Increased Self Consumption of Photovoltaic Power for Electric Vehicle Charging in Virtual Networks". Also additional funding was provided from the research programmes "Electricity and fuel from the sun", the "SolEl programme 2013-2017", both primarily financed by the Swedish Energy Agency.

\section{References}

[1] IEA . Key world energy statistics. International Energy Agency; 2011.

[2] Richardson DB. Electric vehicles and the electric grid: A review of modeling approaches, Impacts, and renewable energy integration. Renew and Sustain Energy Rev 2013;19:247-54.

[3] European Commission . A policy framework for climate and energy in the period from 2020 to 2030. European Commission; 2014.

[4] Tran M, Banister D, Bishop JDK, McCulloch MD. Realizing the electric-vehicle revolution. Nat climate change $2012 ; 2(5): 328-33$.

[5] Munkhammar J, Bishop JDK, Sarralde JJ, Tian W, Choudhary R. Household electricity use, electric vehicle homecharging and distributed photovoltaic power production in the city of Westminster. Energy and Build 2015;86:439-48.

[6] Office of Energy Efficiency \& Renewable Energy . global plug-in light vehicle sales increased by about $80 \%$ in 2015 , Fact\#918 data sheet, US department of energy. 2016.

[7] IEA . Tracking Clean Energy Progress 2017. International Energy Agency; 2017.

[8] Yong JY, Ramachandaramurthy VK, Tan KM, Mithulananthan N. A review on the state-of-the-art technologies of electric vehicle, its impacts and prospects. Renew and Sustain Energy Rev 2015;49:365-85.

[9] Clean Energy Ministerial . Electric Vehicles Initiative (EVI). 2016. URL: http://www.cleanenergyministerial.org/ Our-Work/Initiatives/Electric-Vehicles; [accessed 2016-10-17].

[10] IEA . Global EV outlook: Beyond one million electric cars. International Energy Agency; 2016.

[11] IEA . Global EV outlook: Two million and counting. International Energy Agency; 2017.

[12] IEA . Technology roadmap: Electric and plug-in hybrid electric vehicles. International Energy Agency; 2011.

[13] IEA-PVPS. Snapshot of global photovoltaics market. International Energy Agency; 2017.

[14] IEA-PVPS . Snapshot of global photovoltaics market. International Energy Agency; 2016.

[15] IEA PVPS. Trends in photovoltaic applications: Survey report of selected IEA countries between 1992 and 2015. International Energy Agency; 2016.

[16] Bollen MH, Hassan F. Integration of distributed generation in the power system; vol. 80. Hobiken (NJ): John Wiley \& Sons; 2011.

[17] Munkhammar J, Grahn P, Widén J. Quantifying self-consumption of on-site photovoltaic power generation in households with electric vehicle home charging. Sol Energy 2013;97:208-16.

[18] Denholm P, Kuss M, Margolis RM. Co-benefits of large scale plug-in hybrid electric vehicle and solar PV deployment. J of Power Sources 2013;236:350-6.

[19] Giannouli M, Yianoulis P. Study on the incorporation of photovoltaic systems as an auxiliary power source for hybrid and electric vehicles. Sol Energy 2012;86(1):441-51.

[20] Fattori F, Anglani N, Muliere G. Combining photovoltaic energy with electric vehicles, smart charging and vehicle-to-grid. Sol Energy 2014;110:438-51.

[21] Grahn P, Munkhammar J, Widén J, Alvehag K, Söder L. PHEV home-charging model based on residential activity patterns. IEEE Trans on power Syst 2013;28(3):2507-15.

[22] Munkhammar J, Widén J, Rydén J. On a probability distribution model combining household power consumption, electric vehicle home-charging and photovoltaic power production. Appl Energy 2015;142:135-43.

[23] Luthander R, Widén J, Nilsson D, Palm J. Photovoltaic self-consumption in buildings: A review. Appl Energy $2015 ; 142: 80-94$.

[24] Hayn M, Bertsch V, Fichtner W. Electricity load profiles in Europe: The importance of household segmentation. Energy Res \& Soc Science 2014;3(Supplement C):30 - 45.

[25] Grandjean A, Adnot J, Binet G. A review and an analysis of the residential electric load curve models. Renew and Sust Energy Rev 2012;16(9):6539-65.

[26] Fischer D, Härtl A, Wille-Haussmann B. Model for electric load profiles with high time resolution for German households. Energy and Build 2015;92(Supplement C):170 -9.

[27] Weron R. Electricity price forecasting: A review of the state-of-the-art with a look into the future. Int J of Forecast $2014 ; 30(4): 1030-81$.

[28] Tuffner FK, Chassin FS, Kintner-Meyer MCW, Gowri K. Utilizing Electric Vehicles to Assist Integration of Large Penetrations of Distributed Photovoltaic Generation Capacity. Pacific Northwest National Laboratory; 2012.

[29] Iwai N, Kurahashi N, Kishita Y, Yamaguchi Y, Shimoda Y, Fukushige S, et al. Scenario Analysis of Regional Electricity Demand in the Residential and Commercial Sectors-influence of Diffusion of Photovoltaic Systems and Electric Vehicles into Power Grids. Procedia CIRP 2014;15:319-24.

[30] Galus MD, Zima M, Andersson G. On integration of plug-in hybrid electric vehicles into existing power system structures. Energy Policy 2010;38(11):6736-45. 
[31] Quirós-Tortós J, Ochoa LF, Lees B. A statistical analysis of EV charging behavior in the UK. In: Innov Smart Grid Technol Lat Am (ISGT LATAM), 2015 IEEE PES. 2015, p. 445-9.

[32] Shareef H, Islam MM, Mohamed A. A review of the stage-of-the-art charging technologies, placement methodologies, and impacts of electric vehicles. Renew and Sustain Energy Rev 2016;64:403-20.

[33] Inman RH, Pedro HT, Coimbra CF. Solar forecasting methods for renewable energy integration. Prog in Energy and Combust Science 2013;39(6):535 -76.

[34] Antonanzas J, Osorio N, Escobar R, Urraca R, de Pison FM, Antonanzas-Torres F. Review of photovoltaic power forecasting. Sol Energy 2016;136:78 - 111.

[35] Botero AF, Rios MA. Demand forecasting associated with electric vehicle penetration on distribution systems. In: 2015 IEEE Eindh PowerTech. 2015, p. 1-6.

[36] Majidpour M, Qiu C, Chu P, Pota HR, Gadh R. Forecasting the EV charging load based on customer profile or station measurement? Appl Energy 2016;163(Supplement C):134 -41.

[37] Arias MB, Bae S. Electric vehicle charging demand forecasting model based on big data technologies. Appl Energy 2016;183(Supplement C):327 -39.

[38] Bright JM, Babacan O, Kleissl J, Taylor PG, Crook R. A synthetic, spatially decorrelating solar irradiance generator and application to a LV grid model with high PV penetration. Sol Energy 2017;147(Supplement C):83 - 98.

[39] Widén J, Shepero M, Munkhammar J. On the properties of aggregate clear-sky index distributions and an improved model for spatially correlated instantaneous solar irradiance. Sol Energy 2017;157(Supplement C):566 -80.

[40] Widén J. A model of spatially integrated solar irradiance variability based on logarithmic station-pair correlations. Sol Energy 2015;122(Supplement C):1409 -24.

[41] Lave M, Kleissl J, Stein JS. A wavelet-based variability model (WVM) for solar PV power plants. IEEE Trans on Sustain Energy 2013;4(2):501-9.

[42] Perez R, Hoff TE. Chapter 6: Solar resource variability. In: Kleissl J, editor. Solar Energy Forecasting and Resource Assessment. Boston: Academic Press; 2013, p. 133-48.

[43] Widén J, Carpman N, Castellucci V, Lingfors D, Olauson J, Remouit F, et al. Variability assessment and forecasting of renewables: A review for solar, wind, wave and tidal resources. Renew and Sustain Energy Rev 2015;44:356-75.

[44] Otani K, Minowa J, Kurokawa K. Study on areal solar irradiance for analyzing areally-totalized PV systems. Sol Energy Mater and Sol Cells 1997;47:281-8.

[45] Kawasaki N, Oozeki T, Otani K, Kurokawa K. An evaluation method of the fluctuation characteristics of photovoltaic systems by using frequency analysis. Sol Energy Mater and Sol Cells 2006;90:3356-63.

[46] Lave M, Kleissl J, Arias-Castro E. High-frequency irradiance fluctuations and geographic smoothing. Sol Energy 2012;86(8):2190-9.

[47] Perez R, Kivalov S, Schlemmer J, Hemker K, Hoff TE. Short-term irradiance variability: Preliminary estimation of station pair correlation as a function of distance. Sol Energy 2012;86(8):2170-6.

[48] Hinkelman LM. Differences between along-wind and cross-wind solar irradiance variability on small spatial scales. Sol Energy 2013;88:192-203.

[49] Wiemken E, Beyer H, Heydenreich W, Kiefer K. Power characteristics of PV ensembles: experiences from the combined power production of 100 grid connected PV systems distributed over the area of Germany. Sol Energy 2001;70(6):513-8.

[50] Murata A, Yamaguchi H, Otani K. A method of estimating the output fluctuation of many photovoltaic power generation systems dispersed in a wide area. Electr Eng in Jpn 2009;166(4):9-19.

[51] Marcos J, Marroyo L, Lorenzo E, Alvira D, Izco E. Power output fluctuations in large scale PV plants: One year observations with one second resolution and a derived analytic model. Prog in Photovolt: Res and Appl 2011;19(2):21827.

[52] van Haaren R, Morjaria M, Fthenakis V. Empirical assessment of short-term variability from utility-scale solar PV plants. Prog in Photovolt: Res and Appl 2012;22:548-59.

[53] Widén J. A model of spatially integrated solar irradiance variability based on logarithmic station-pair correlations. Sol Energy 2015;122:1409-24.

[54] Inman RH, Pedro HT, Coimbra CF. Solar forecasting methods for renewable energy integration. Prog in Energy and Combust Science 2013;39(6):535-76.

[55] Yang D, Gu C, Dong Z, Jirutitijaroen P, Chen N, Walsh WM. Solar irradiance forecasting using spatial-temporal covariance structures and time-forward kriging. Renew Energy 2013;60:235 -45.

[56] Aryaputera AW, Yang D, Zhao L, Walsh WM. Very short-term irradiance forecasting at unobserved locations using spatio-temporal kriging. Sol Energy 2015;122:1266 -78.

[57] Hoff TE, Perez R. Quantifying PV power output variability. Sol Energy 2010;84(10):1782-93.

[58] Perez R, Kivalov S, Schlemmer J, Hemker Jr. K, Hoff T. Parameterization of site-specific short-term irradiance variability. Sol Energy 2011;85(7):1343-53.

[59] Hoff TE, Perez R. Modeling PV fleet output variability. Sol Energy 2012;86(8):2177-89.

[60] Lave M, Kleissl J. Cloud speed impact on solar variability scaling - Application to the wavelet variability model. Sol Energy 2013;91:11-21.

[61] Lonij VPA, Brooks AE, Cronin AD, Leuthold M, Koch K. Intra-hour forecasts of solar power production using measurements from a network of irradiance sensors. Sol Energy 2013;97:58-66.

[62] Arias-Castro E, Kleissl J, Lave M. A Poisson model for anisotropic solar ramp rate correlations. Sol Energy 2014;101:192202 .

[63] Ångström A. Note on the relation between time of sunshine and cloudiness in Stockholm 1908-1920. Ark för Mat, Astron och Fys, K vetenskapsakademien 1922;17:1-7. 
[64] Ångström A. Solar and terrestrial radiation. Q J of the R Meteorol Soc 1924;50(210):121-6.

[65] Ångström A. On the computation of global radiation from records of sunshine. Ark fur Geofis 1956;5:471-9.

[66] Black JN, Bonython CW, Prescott JA. Solar radiation and the duration of sunshine. Q J of the R Meteorol Soc $1954 ; 80(344): 231-5$.

[67] Glover J, McCulloch JSG. The empirical relation between solar radiation and hours of sunshine. Q J of the R Meteorol Soc 1958;84(360):172-5.

[68] Bennett I. Frequency of daily insolation in Anglo North America during June and December. Sol Energy 1967;11(1):41-55.

[69] Klein SA. Calculation of monthly average insolation on tilted surfaces. Sol Energy 1977;19(4):325-9.

[70] Andretta A, Bartoli B, Coluzzi B, Cuomo V, Francesca M, Serio C. Global solar radiation estimation from relative sunshine hours in Italy. J of Appl meteorol 1982;21(10):1377-84.

[71] Barbaro S, Cannata G, Coppolino S. Monthly reference distribution of daily relative sunshine values. Sol Energy $1983 ; 31(1): 63-7$.

[72] Liu BYH, Jordan RC. The interrelationship and characteristic distribution of direct, diffuse and total solar radiation. Sol Energy 1960;4(3):1-19.

[73] Bendt P, Collares-Pereira M, Rabl A. The frequency distribution of daily insolation values. Sol Energy 1981;27(1):1-5.

[74] Hollands KGT, Huget RG. A probability density function for the clearness index, with applications. Sol Energy 1983;30(3):195-209.

[75] Saunier GY, Reddy TA, Kumar S. A monthly probability distribution function of daily global irradiation values appropriate for both tropical and temperate locations. Sol Energy 1987;38(3):169-77.

[76] Suehrcke H, McCormick PG. The frequency distribution of instantaneous insolation values. Sol Energy 1988;40(5):413-22.

[77] Suehrcke H. The effect of time errors on the accuracy of solar radiation measurements. Sol Energy 1994;53(4):353 -7.

[78] Jurado M, Caridad J, Ruiz V. Statistical distribution of the clearness index with radiation data integrated over five minute intervals. Sol Energy 1995;55(6):469-73.

[79] Tovar J, Olmo FJ, Alados-Arboledas L. One-minute global irradiance probability density distributions conditioned to the optical air mass. Sol Energy 1998;62(6):387-93.

[80] Ibáñez M, Rosell JI, Beckman WA. A bi-variable probability density function for the daily clearness index. Sol Energy 2003;75(1):73-80.

[81] Munkhammar J, Rydén J, Widén J, Lingfors D. Simulating dispersed photovoltaic power generation using a bimodal mixture model of the clear-sky index. EU-PVSEC, 14-19 September, Hambg; 2015.

[82] Assunção HF, Escobedo JF, Oliveira AP. Modelling frequency distributions of 5 minute-averaged solar radiation indexes using Beta probability functions. Theor and Appl Climatol 2003;75(3-4):213-24.

[83] Assunção HF, Escobedo JF, Oliveira AP. A new algorithm to estimate sky condition based on 5 minutes-averaged values of clearness index and relative optical air mass. Theor and Appl Climatol 2007;90(3-4):235-48.

[84] Hollands KGT, Suehrcke H. A three-state model for the probability distribution of instantaneous solar radiation, with applications. Sol Energy 2013;96:103-12.

[85] Munkhammar J, Widén J. Correlation modeling of instantaneous solar irradiance with applications to solar engineering. Sol Energy 2016;133:14-23.

[86] Nelsen RB. An Introduction to Copulas. Springer Series in Statistics; New York: Springer; 2006.

[87] Hagspiel S, Papaemannouil A, Schmid M, Andersson G. Copula-based modeling of stochastic wind power in Europe and implications for the Swiss power grid. Appl Energy 2012;96:33-44.

[88] Munkhammar J, Widén J. Copula Correlation Modling of Aggregate Solar Irradiance in Spatial Networks. In: 6th Int Sol Integr Workshop in Vienna, 14-15 November 2016. 2016, p. 468-73.

[89] Nũno E, Cutululis N. Spatio-temporal Analysis of Regtional PV Generation. In: 6th Int Sol Integr Workshop in Vienna, 14-15 November 2016. 2016, p. 269-75.

[90] Melius J, Margolis R, Ong S. Estimating rooftop suitability for PV: A review of methods, patents, and validation techniques. Tech. Rep. No. NREL/TP-6A20-60593; National Renewable Energy Laboratory, Golden, CO (USA); 2013.

[91] Lukač N, Žlaus D, Seme S, Žalik B, Štumberger G. Rating of roofs? surfaces regarding their solar potential and suitability for pv systems, based on lidar data. Appl Energy 2013;102:803-12.

[92] Lukač N, Seme S, Žlaus D, Štumberger G, Žalik B. Buildings roofs photovoltaic potential assessment based on LiDAR (Light Detection And Ranging) data. Energy 2014;66:598-609.

[93] Camargo LR, Zink R, Dorner W, Stoeglehner G. Spatio-temporal modeling of roof-top photovoltaic panels for improved technical potential assessment and electricity peak load offsetting at the municipal scale. Computers, Environ and Urban Syst 2015;52:58-69.

[94] Henn A, Gröger G, Stroh V, Plümer L. Model driven reconstruction of roofs from sparse LIDAR point clouds. ISPRS J of Photogramm and Remote Sens 2013;76:17 - 29.

[95] Huang H, Brenner C, Sester M. A generative statistical approach to automatic 3D building roof reconstruction from laser scanning data. ISPRS J of Photogramm and Remote Sens 2013;79:29 - 43.

[96] Gooding J, Crook R, Tomlin AS. Modelling of roof geometries from low-resolution LiDAR data for city-scale solar energy applications using a neighbouring buildings method. Appl Energy 2015;148:93 - 104

[97] Soda-service . Cams McClear Service For Estimating Irradiation under Clear-Sky. 2016. URL: http://www.soda-pro. com/web-services/radiation/cams-mcclear; [accessed 2016-05-05].

[98] Lefevre M, Oumbe A, Blanc P, Espinar B, Gschwind B, Qu Z, et al. McClear: a new model estimating downwelling solar radiation at ground level in clear-sky conditions. Atmospheric Meas Tech 2013;6:2403-18.

[99] Bird RE, Hulstrom RL. Simplified clear sky model for direct and diffuse insolation on horizontal surfaces. Tech. Rep. No. SERI/TR-642-761; Solar Energy Research Institute, Golden, CO (USA); 1981. 
[100] Ineichen P. Long term irradiance clear sky and all-weather model validation. SASEC, 4th South Afr Sol Energy Conf; 2016.

[101] Reno MJ, Hansen CW, Stein JS. Global horizontal irradiance clear sky models: Implementation and analysis. SANDIA report; 2012

[102] Dervishi S, Mahdavi A. Computing diffuse fraction of global horizontal solar radiation: A model comparison . Sol Energy 2012;86(6):1796-802.

[103] Erbs DG, Klein SA, Duffie JA. Estimation of the diffuse radiation fraction for hourly, daily and monthly-average global radiation. Sol Energy 1982;28(4):293-302.

[104] Loutzenhiser P, Manz H, Felsmann C, Strachan P, Frank T, Maxwell G. Empirical validation of models to compute solar irradiance on inclined surfaces for building energy simulation. Sol Energy 2007;81(2):254-67.

[105] Gueymard CA. Direct and indirect uncertainties in the prediction of tilted irradiance for solar engineering applications. Sol Energy 2009;83(3):432 -44.

[106] Hay JE. Calculation of monthly mean solar radiation for horizontal and inclined surfaces. Sol Energy 1979;23(4):301 -7.

[107] Perez R, Ineichen P, Seals R, Michalsky J, Stewart R. Modeling daylight availability and irradiance components from direct and global irradiance. Sol Energy 1990;44(5):271 -89.

[108] Klise GT, Stein JS. Models used to assess the performance of photovoltaic systems. Tech. Rep. No. SAND2009-8258; Sandia National Laboratories; 2009.

[109] Evans D. Simplified method for predicting photovoltaic array output. Sol Energy 1981;27(6):555 -60.

[110] Mattei M, Notton G, Cristofari C, Muselli M, Poggi P. Calculation of the polycrystalline PV module temperature using a simple method of energy balance. Renew Energy 2006;31(4):553-67.

[111] King DL, Gonzalez S, Galbraith GM, Boyson WE. Performance model for grid-connected photovoltaic inverters. Tech. Rep. No. SAND2007-5036; Sandia National Laboratories; 2007.

[112] Carigiet F, Niedrist M, Scheuermann C, Baumgartner F. Case study of a low-voltage distribution grid with high PV penetration in Germany and simulation analyses of cost-effective measures. Prog in Photovolt: Res and Appl 2016;24(12):1523-32.

[113] Tonkoski R, Lopes LA, El-Fouly TH. Coordinated active power curtailment of grid connected PV inverters for overvoltage prevention. IEEE Trans on Sustain Energy 2011;2(2):139-47.

[114] Liu Y, Bebic J, Kroposki B, De Bedout J, Ren W. Distribution system voltage performance analysis for high-penetration PV. In: 2008 IEEE Energy 2030 Conf. 2008, p. 1-8.

[115] Tonkoski R, Turcotte D, El-Fouly TH. Impact of high PV penetration on voltage profiles in residential neighborhoods. IEEE Trans on Sustain Energy 2012;3(3):518-27.

[116] Stewart E, MacPherson J, Vasilic S, Nakafuji D, Aukai T. Analysis of High-Penetration Levels of Photovoltaics into the Distribution Grid on Oahu, Hawaii. Tech. Rep. No. SR-5500-54494; National Renewable Energy Laboratory (NREL), Golden, CO (USA); 2013.

[117] Braun M, Stetz T, Bründlinger R, Mayr C, Ogimoto K, Hatta H, et al. Is the distribution grid ready to accept largescale photovoltaic deployment? state of the art, progress, and future prospects. Prog in Photovolt: Res and Appl 2012;20(6):681-97.

[118] Walla T, Widén J, Johansson J, Bergerland C. Determining and increasing the hosting capacity for photovoltaics in Swedish distribution grids. Proc of the 27th Eur Photovolt Energy Conf (EU-PVSEC), Frankf, Ger, September 24-28, $2012 ; 2012$.

[119] Schallenberg RH. Prospects for the electric vehicle: A historical perspective. IEEE Trans on Educ 1980;23(3):137-43.

[120] Heydt G. The impact of electric vehicle deployment on load management strategies. IEEE Trans on Power Appar and Syst $1983 ;(5): 1253-9$

[121] Stafford KA, DeWispelare AR. Electric vehicle energy use simulation model. In: Conf Proc Southeastcon'81. 1981, p. 544-8.

[122] Van Roy J, Leemput N, De Breucker S, Geth F, Tant P, Driesen J. An availability analysis and energy consumption model for a Flemish fleet of electric vehicles. In: Eur electr veh congr (EVVC). 2011, p. 1-12.

[123] Peres LAP, Lambert-Torres G, Nogueira LAH. Electric vehicles impacts on daily load curves and environment. In: Int Conf on Electr Power Eng, 1999 PowerTech Bp 99. 1999, p. 55-9.

[124] Koyanagi F, Uriu Y. Modeling power consumption by electric vehicles and its impact on power demand. Electr Eng in Jpn 1997;120(4):40-7.

[125] Ford A. The impacts of large scale use of electric vehicles in southern California. Energy and Build 1995;22(3):207-18.

[126] Heider A, Haubrich HJ. Impact of wide-scale EV charging on the power supply network. In: IEE Colloq on Electr Veh-A Tech Roadmap for the Future (Digest No 1998/262). 1998, p. 1-4.

[127] Koyanagi F, Uriu Y. A strategy of load leveling by charging and discharging time control of electric vehicles. IEEE Trans on power Syst 1998;13(3):1179-84.

[128] Sugii Y, Tsujino K, Nagano T. A genetic-algorithm based scheduling method of charging electric vehicles. In: 1999 IEEE Int Conf on Syst, Man, and Cybern, 1999 IEEE SMC'99 Conf Proc; vol. 4. 1999, p. 435-40.

[129] Lopes JAP, Soares FJ, Almeida PMR, Moreira CL, Seca L. A stochastic model to simulate electric vehicles motion and quantify the energy required from the grid. Proc of the 17th Power Syst Comput Conf (PSCC), Stockh, Swed; 2011.

[130] Hill G, Blythe PT, Higgins C. Deviations in Markov chain modeled electric vehicle charging patterns from real world data. In: 2012 15th Int IEEE Conf on Intell Transp Syst. 2012, p. 1072-7.

[131] Bae S, Kwasinski A. Spatial and temporal model of electric vehicle charging demand. IEEE Trans on Smart Grid 2012;3(1):394-403.

[132] Farkas C, Prikler L. Stochastic modelling of EV charging at charging stations. In: Int conf on renew energies and power 
qual ICREPQ, Santiago de Compostela. 2012, p. 28-30.

[133] Zhang X, Grijalva S. An advanced data driven model for residential electric vehicle charging demand. In: 2015 IEEE Power \& Energy Soc Gen Meet. 2015, p. 1-5.

[134] Srinivasaraghavan S, Khaligh A. Deterministic scheduling of a fleet of plug-in hybrid vehicles for distributed generation. IEEE Power and Energy Mag 2011;9(4):46-53.

[135] Brady J, O'Mahony M. Modelling charging profiles of electric vehicles based on real-world electric vehicle charging data. Sustain Cities and Soc 2016;26:203-16.

[136] Kim J, Son SY, Lee JM, Ha HT. Scheduling and performance analysis under a stochastic model for electric vehicle charging stations. Omega 2017;66, Part B:278 -89.

[137] Sortomme E, Negash AI, Venkata SS, Kirschen DS. Multistate voltage dependent load model of a charging electric vehicle. In: 2012 IEEE Transp Electrification Conf and Expo (ITEC). 2012, p. 1-5.

[138] Wei Z, He J, Cai L. Admission Control and Scheduling for EV Charging Station Considering Time-of-Use Pricing. In: 2016 IEEE 83rd Veh Tech Conf (VTC Spring). 2016, p. 1-5.

[139] Xydas E, Marmaras C, Cipcigan LM, Jenkins N, Carroll S, Barker M. A data-driven approach for characterising the charging demand of electric vehicles: A UK case study. Appl Energy 2016;162:763-71.

[140] Gödde M, Findeisen T, Sowa T, Nguyen PH. Modelling the charging probability of electric vehicles as a gaussian mixture model for a convolution based power flow analysis. In: PowerTech, 2015 IEEE Eindh. 2015, p. 1-6.

[141] Yunus K, De La Parra HZ, Reza M. Distribution grid impact of Plug-In Electric Vehicles charging at fast charging stations using stochastic charging model. In: Proc of the 2011-14th Eur Conf on Power Electron and Appl (EPE 2011). 2011 , p. $1-11$.

[142] Leou RC, Su CL, Lu CN. Stochastic analyses of electric vehicle charging impacts on distribution network. IEEE Trans on power Syst 2014;29(3):1055-63.

[143] Mu Y, Wu J, Jenkins N, Jia H, Wang C. A spatial-temporal model for grid impact analysis of plug-in electric vehicles. Appl Energy 2014;114:456-65.

[144] Leou RC, Teng JH, Su CL. Modelling and verifying the load behaviour of electric vehicle charging stations based on field measurements. IET Gener, Transm \& Distribution 2015;9(11):1112-9.

[145] Ansari M, Al-Awami AT, Abido MA, Sortomme E. Optimal charging strategies for unidirectional vehicle-to-grid using fuzzy uncertainties. In: 2014 IEEE PES T\&D Conf and Expo. 2014, p. 1-5.

[146] Qian K, Zhou C, Allan M, Yuan Y. Modeling of load demand due to EV battery charging in distribution systems. IEEE Trans on power Syst 2011;26(2):802-10.

[147] Valsera-Naranjo E, Martinez-Vicente D, Sumper A, Villafafila-Robles R, Sudrià-Andreu A. Deterministic and probabilistic assessment of the impact of the electrical vehicles on the power grid. In: 2011 IEEE Power \& Energy Soc Gen Meet. 2011, p. 1-8.

[148] Kristoffersen TK, Capion K, Meibom P. Optimal charging of electric drive vehicles in a market environment. Appl Energy 2011;88(5):1940-8.

[149] Steen D, Le T, Ortega-Vazquez M, Carlson O, Bertling L, Viktoria N. Scheduling charging of electric vehicles for optimal distribution systems planning and operation. CIRED 21st Int Conf on Electr Distribution, Frankf, 6-9 June $2011 ; 2011$.

[150] Axsen J, Kurani KS, McCarthy R, Yang C. Plug-in hybrid vehicle GHG impacts in California: Integrating consumerinformed recharge profiles with an electricity-dispatch model. Energy Policy 2011;39(3):1617-29.

[151] Verzijlbergh RA, Grond MOW, Lukszo Z, Slootweg JG, Ilic MD. Network impacts and cost savings of controlled EV charging. IEEE Trans on Smart Grid 2012;3(3):1203-12.

[152] Lopes JAP, Soares FJ, Almeida PMR. Integration of electric vehicles in the electric power system. Proc of the IEEE 2011;99(1):168-83.

[153] Steen D, Tuan LA, Carlson O, Bertling L. Assessment of electric vehicle charging scenarios based on demographical data. IEEE Trans on Smart Grid 2012;3(3):1457-68.

[154] Paevere P, Higgins A, Ren Z, Horn M, Grozev G, McNamara C. Spatio-temporal modelling of electric vehicle charging demand and impacts on peak household electrical load. Sustain sci 2014;9(1):61-76.

[155] Wu D, Aliprantis DC, Gkritza K. Electric energy and power consumption by light-duty plug-in electric vehicles. IEEE Trans on power Syst 2011;26(2):738-46.

[156] Kara EC, Macdonald JS, Black D, Bérges M, Hug G, Kiliccote S. Estimating the benefits of electric vehicle smart charging at non-residential locations: A data-driven approach. Appl Energy 2015;155:515-25.

[157] Su W, Eichi H, Zeng W, Chow MY. A survey on the electrification of transportation in a smart grid environment. IEEE Trans on Ind Inform 2012;8(1):1-10.

[158] Vasant PM, Rahman I, Singh Mahinder Singh B, Abdullah-Al-Wadud M. Optimal power allocation scheme for plug-in hybrid electric vehicles using swarm intelligence techniques. Cogent Eng 2016;3(1):1203083.

[159] Haidar AMA, Muttaqi KM. Behavioral characterization of electric vehicle charging loads in a distribution power grid through modeling of battery chargers. In: 2014 IEEE Ind Appl Soc Annu Meet. 2014, p. 1-8.

[160] Dharmakeerthi C, Mithulananthan N, Saha TK. Modeling and planning of EV fast charging station in power grid. In: 2012 IEEE Power \& Energy Soc Gen Meet. 2012, p. 1-8.

[161] Gücin TN, Biberoglu M, Fincan B. A constant-current constant-voltage charging based control and design approach for the parallel resonant converter. In: 2015 Int Conf on Renew Energy Res and Appl (ICRERA). 2015, p. 414-9.

[162] Kuperman A, Levy U, Goren J, Zafranski A, Savernin A, Peled I. Modeling and control of a 50KW electric vehicle fast charger. In: 2010 IEEE 26th Conv of Electr and Electron Eng in Isr (IEEEI). 2010, p. 000188-9.

[163] Fan Y, Zhang H, Shi F. Modeling of electric vehicle loads applicable to power system quasi-steady state analysis. In: 2015 5th Int Conf on Electr Util Deregul and Restruct and Power Tech (DRPT). 2015, p. 301-5. 
[164] O'Connell A, Flynn D, Keane A. Rolling multi-period optimization to control electric vehicle charging in distribution networks. IEEE Trans on power Syst 2014;29(1):340-8.

[165] Clement-Nyns K, Haesen E, Driesen J. The impact of charging plug-in hybrid electric vehicles on a residential distribution grid. IEEE Trans on power Syst 2010;25(1):371-80.

[166] IEA . Electricity information. International Energy Agency; 2016.

[167] Taylor J, Maitra A, Alexander M, Brooks D, Duvall M. Evaluation of the impact of plug-in electric vehicle loading on distribution system operations. In: 2009 IEEE Power \& Energy Soc Gen Meet. 2009, p. 1-6.

[168] Babaei S, Steen D, Tuan LA, Carlson O, Bertling L. Effects of Plug-in Electric Vehicles on distribution systems: A real case of Gothenburg. In: 2010 IEEE PES Innov Smart Grid Tech Conf Eur (ISGT Eur). 2010, p. 1-8.

[169] Falahati S, Taher SA, Shahidehpour M. Grid frequency control with electric vehicles by using of an optimized fuzzy controller. Appl Energy 2016;178:918-28.

[170] Falahati S, Taher SA, Shahidehpour M. A new smart charging method for EVs for frequency control of smart grid. Int J of Electr Power \& Energy Syst 2016;83:458-69.

[171] Fernandez LP, San Roman TG, Cossent R, Domingo CM, Frías P. Assessment of the impact of plug-in electric vehicles on distribution networks. IEEE Trans on power Syst 2011;26(1):206-13.

[172] Will C, Schuller A. Understanding user acceptance factors of electric vehicle smart charging. Transp Res Part C: Emerg Tech 2016;71:198-214.

[173] García-Villalobos J, Zamora I, Knezović K, Marinelli M. Multi-objective optimization control of plug-in electric vehicles in low voltage distribution networks. Appl Energy 2016;180:155-68.

[174] Esmaili M, Rajabi M. Optimal charging of plug-in electric vehicles observing power grid constraints. IET Gener, Transm \& Distribution 2014;8(4):583-90.

[175] Sundstrom O, Binding C. Flexible charging optimization for electric vehicles considering distribution grid constraints. IEEE Trans on Smart Grid 2012;3(1):26-37.

[176] Huo H, Cai H, Zhang Q, Liu F, He K. Life-cycle assessment of greenhouse gas and air emissions of electric vehicles: A comparison between China and the US. Atmospheric Environ 2015;108:107-16.

[177] Yuksel T, Tamayao MAM, Hendrickson C, Azevedo IM, Michalek JJ. Effect of regional grid mix, driving patterns and climate on the comparative carbon footprint of gasoline and plug-in electric vehicles in the United States. Environ Res Lett 2016;11(4):044007.

[178] Hawkins TR, Singh B, Majeau-Bettez G, Strømman AH. Comparative environmental life cycle assessment of conventional and electric vehicles. J of Ind Ecol 2013;17(1):53-64.

[179] Sioshansi R, Miller J. Plug-in hybrid electric vehicles can be clean and economical in dirty power systems. Energy Policy 2011;39(10):6151-61.

[180] Speidel S, Bräunl T. Driving and charging patterns of electric vehicles for energy usage. Renew and Sustain Energy Rev 2014;40:97-110.

[181] Buekers J, Van Holderbeke M, Bierkens J, Panis LI. Health and environmental benefits related to electric vehicle introduction in EU countries. Transp Res Part D: Transp and Environ 2014;33:26-38.

[182] Li C, Cao Y, Zhang M, Wang J, Liu J, Shi H, et al. Hidden benefits of electric vehicles for addressing climate change. Sci rep 2015;5:1-4.

[183] Parks K, Denholm P, Markel AJ. Costs and emissions associated with plug-in hybrid electric vehicle charging in the Xcel Energy Colorado service territory. Tech. Rep. No. NREL/TP-640-41410; National Renewable Energy Laboratory Golden, CO; 2007.

[184] Mills G, MacGill I. Assessing greenhouse gas emissions from electric vehicle operation in Australia using temporal vehicle charging and electricity emission characteristics. Int J of Sustain Transp 2017;11(1):20-30.

[185] von Wirth T, Gislason L, Seidl R. Distributed energy systems on a neighborhood scale: Reviewing drivers of and barriers to social acceptance. Renew and Sust Energy Rev 2017;URL: http://www.sciencedirect.com/science/article/pii/ S1364032117313412. doi:https://doi.org/10.1016/j.rser.2017.09.086.

[186] Birnie III DP. Solar-to-vehicle (S2V) systems for powering commuters of the future. J of Power Sources 2009;186(2):53942 .

[187] O'Brien WT, Kennedy CA, Athienitis AK, Kesik TJ. The Relationship between Net Energy Use and the Urban Density of Solar Buildings. Environ and Planning B: Plan and Des 2010;37(6):1002-21.

[188] Ko Y, Jang K, Radke JD. Toward a solar city: Trade-offs between on-site solar energy potential and vehicle energy consumption in San Francisco, California. Int J of Sust Transp 2017;11(6):460-70.

[189] Byrd H, Ho A, Sharp B, Kumar-Nair N. Measuring the solar potential of a city and its implications for energy policy. Energy Policy 2013;61(Supplement C):944 -52.

[190] Neumann HM, Schär D, Baumgartner F. The potential of photovoltaic carports to cover the energy demand of road passenger transport. Prog in Photovolt: Res and Appl 2012;20(6):639-49.

[191] Brenna M, Dolara A, Foiadelli F, Leva S, Longo M. Urban scale photovoltaic charging stations for electric vehicles. IEEE Trans on Sustain Energy 2014;5(4):1234-41.

[192] Mouli GRC, Bauer P, Zeman M. System design for a solar powered electric vehicle charging station for workplaces. Appl Energy 2016;168:434-43.

[193] Miceli R, Viola F. Designing a sustainable university recharge area for electric vehicles: Technical and economic analysis. Energies 2017;10(10):1604.

[194] Marra F, Yang GY, Traeholt C, Larsen E, Ostergaard J, Blazic B, et al. EV charging facilities and their application in LV feeders with photovoltaics. IEEE Trans on Smart Grid 2013;4(3):1533-40.

[195] Derakhshandeh SY, Masoum AS, Deilami S, Masoum MAS, Hamedani Golshan M. Coordination of generation scheduling 
with PEVs charging in industrial microgrids. IEEE Trans on Power Syst 2013;28(3):3451-61.

[196] Chaouachi A, Bompard E, Fulli G, Masera M, De Gennaro M, Paffumi E. Assessment framework for EV and PV synergies in emerging distribution systems. Renew and Sustain Energy Rev 2016;55:719-28.

[197] Zhang Q, Tezuka T, Ishihara KN, Mclellan BC. Integration of PV power into future low-carbon smart electricity systems with EV and HP in Kansai Area, Japan. Renew Energy 2012;44:99-108.

[198] Rahmani-andebili M. Optimal power factor for optimally located and sized solar parking lots applying quantum annealing. IET Gener, Transm \& Distribution 2016;10(10):2538-47.

[199] Tulpule PJ, Marano V, Yurkovich S, Rizzoni G. Economic and environmental impacts of a PV powered workplace parking garage charging station. Appl Energy 2013;108:323-32.

[200] Locment F, Sechilariu M, Forgez C. Electric vehicle charging system with PV grid-connected configuration. In: 2010 IEEE Veh Power and Propuls Conf. 2010, p. 1-6.

[201] Honarmand M, Zakariazadeh A, Jadid S. Optimal scheduling of electric vehicles in an intelligent parking lot considering vehicle-to-grid concept and battery condition. Energy 2014;65:572-9.

[202] Goli P, Shireen W. PV powered smart charging station for PHEVs. Renew Energy 2014;66:280-7.

[203] Honarmand M, Zakariazadeh A, Jadid S. Integrated scheduling of renewable generation and electric vehicles parking lot in a smart microgrid. Energy Convers and Manag 2014;86:745-55.

[204] Honarmand M, Zakariazadeh A, Jadid S. Self-scheduling of electric vehicles in an intelligent parking lot using stochastic optimization. J of the Frankl Inst 2015;352(2):449-67.

[205] Tahara H, Urasaki N, Senjyu T, Funabashi T. EV charging station using renewable energy. In: 2016 IEEE First Int Conf on Control, Meas and Instrum (CMI). 2016, p. 48-52.

[206] García-Triviño P, Fernández-Ramírez LM, Torreglosa JP, Jurado F. Control of electric vehicles fast charging station supplied by PV/energy storage system/grid. In: 2016 IEEE Int Energy Conf (ENERGYCON). 2016, p. 1-6.

[207] Alafnan H, Zhao J, Ma W. Prevention of overvoltage induced by large penetration of photovoltaics in distribution networks by electric vehicles. In: 2016 IEEE Transp Electr Conf and Expo, Asia-Pac (ITEC Asia-Pac). 2016, p. 525-30.

[208] Liu N, Zou F, Wang L, Wang C, Chen Z, Chen Q. Online energy management of PV-assisted charging station under time-of-use pricing. Electr Power Syst Res 2016;137:76-85.

[209] Kuang Y, Chen Y, Hu M, Yang D. Influence analysis of driver behavior and building category on economic performance of electric vehicle to grid and building integration. 2017.

[210] Van Roy J, Leemput N, Geth F, Büscher J, Salenbien R, Driesen J. Electric vehicle charging in an office building microgrid with distributed energy resources. IEEE Trans on Sustain Energy 2014;5(4):1389-96.

[211] Mwasilu F, Justo JJ, Kim EK, Do TD, Jung JW. Electric vehicles and smart grid interaction: A review on vehicle to grid and renewable energy sources integration. Renew and Sustain Energy Rev 2014;34:501-16.

[212] Drude L, Junior LCP, Rüther R. Photovoltaics (PV) and electric vehicle-to-grid (V2G) strategies for peak demand reduction in urban regions in Brazil in a smart grid environment. Renew Energy 2014;68:443-51.

[213] Thomas D, Deblecker O, Ioakimidis CS. Optimal operation of an energy management system for a grid-connected smart building considering photovoltaics' uncertainty and stochastic electric vehicles' driving schedule. Appl Energy 2017;doi:https://doi.org/10.1016/j.apenergy.2017.07.035.

[214] Sengupta M, Andreas A. Oahu Solar Measurement Grid (1-Year Archive): 1-Second Solar Irradiance; Oahu, Hawaii (Data). Tech. Rep. No. DA-5500-56506; National Renewable Energy Laboratory (NREL), Golden, CO (USA); 2010. 


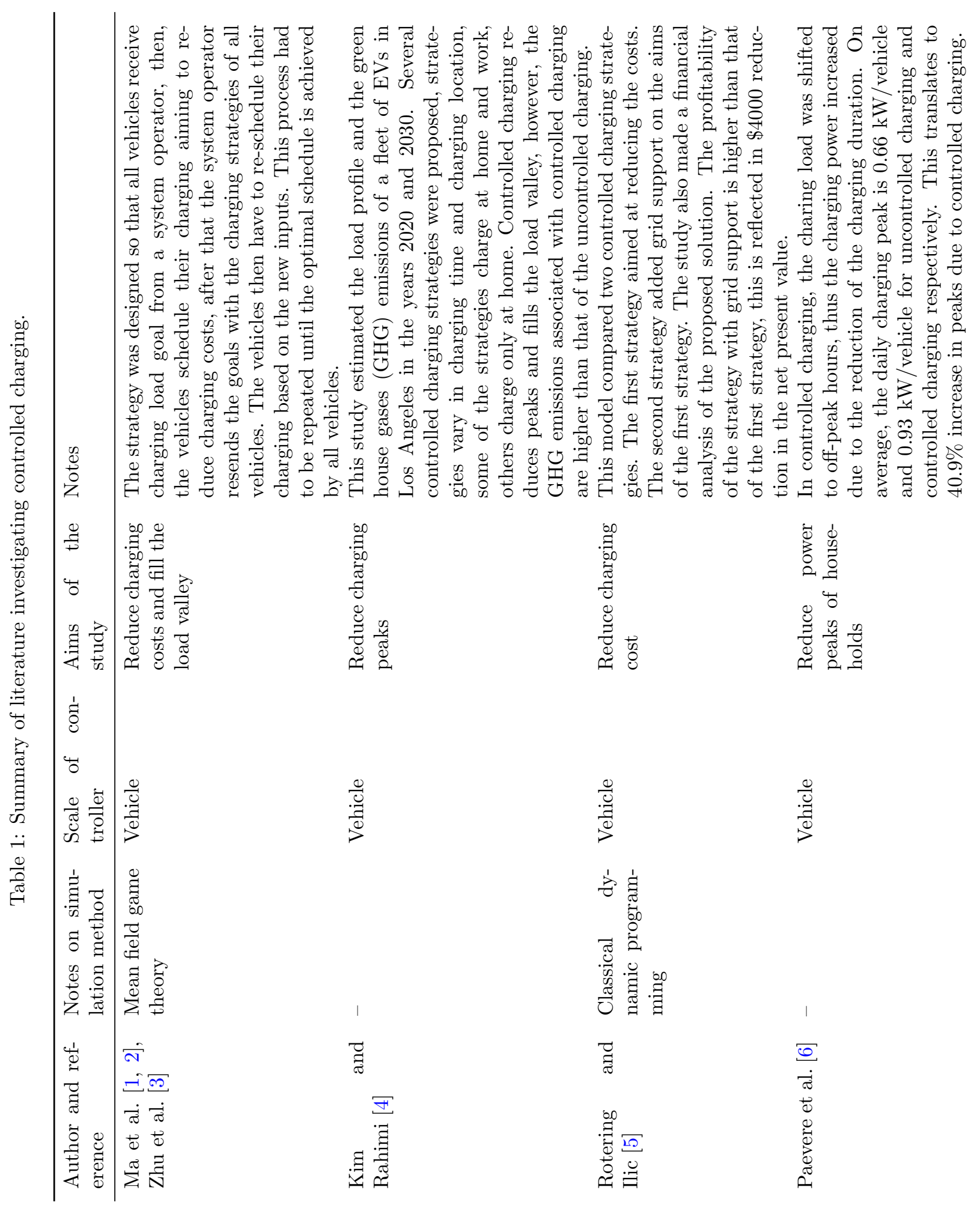




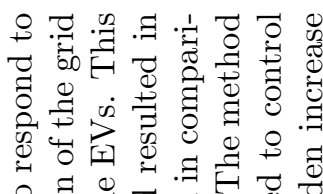

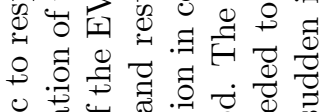

.

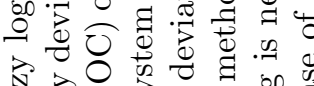

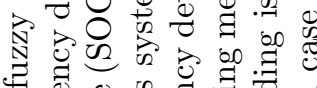

击

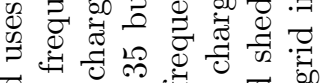

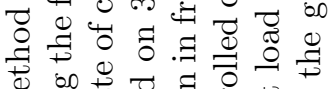

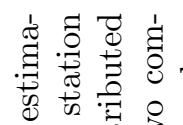

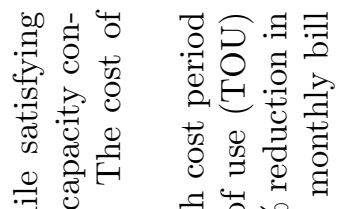

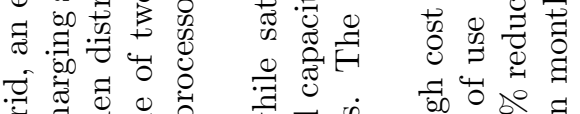

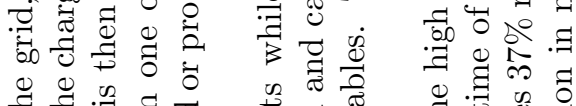

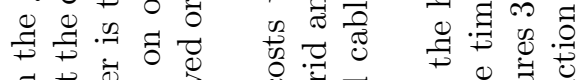

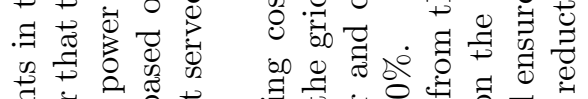

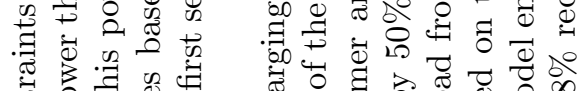

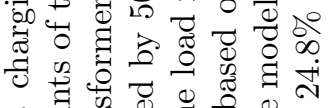

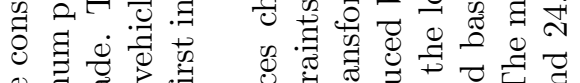

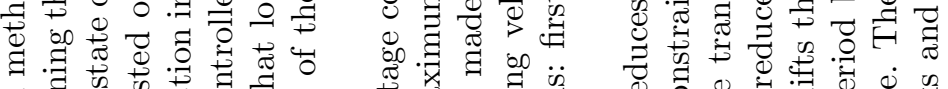

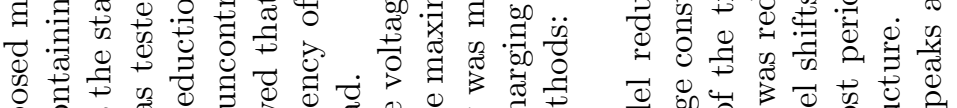

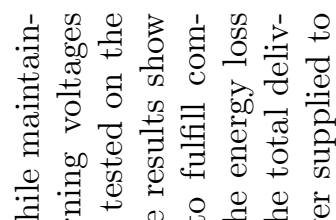

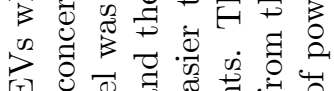

4 क

.

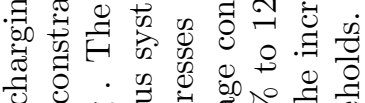
বी 8 s.

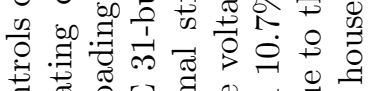

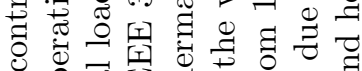

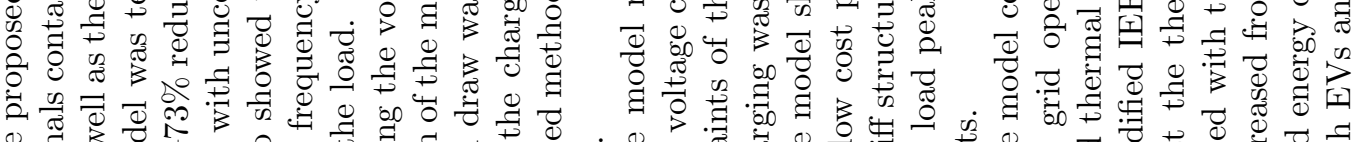

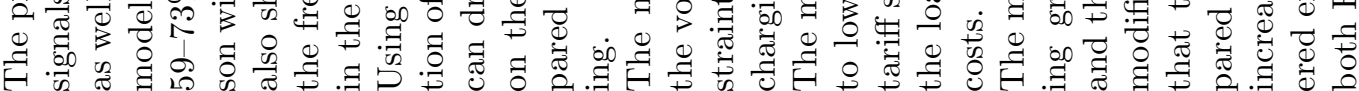

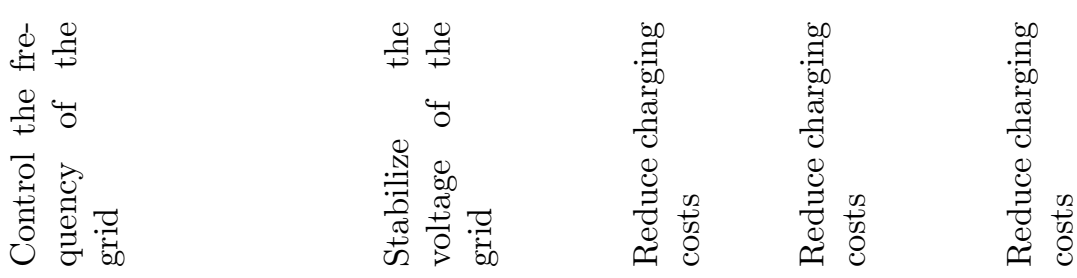

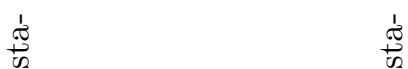

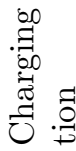

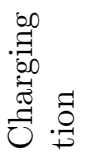

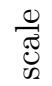

密

$\stackrel{1}{\circ}$

:

$\stackrel{0}{.0}$

空

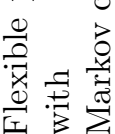

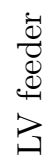

0
0
0
0
0
0.0
80
4

5
5
0
00
0
50
00
4

๘ं

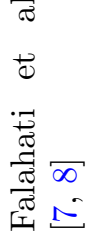

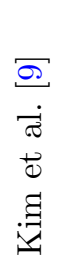

के

:

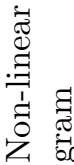

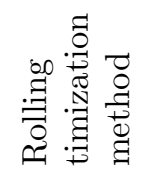

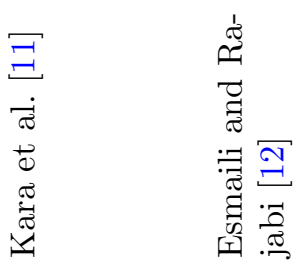




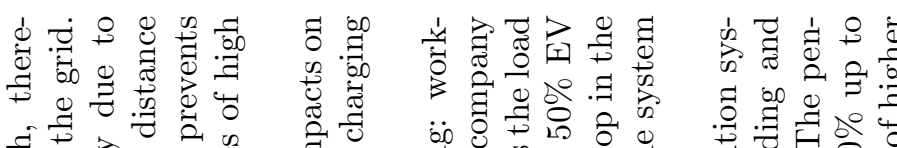

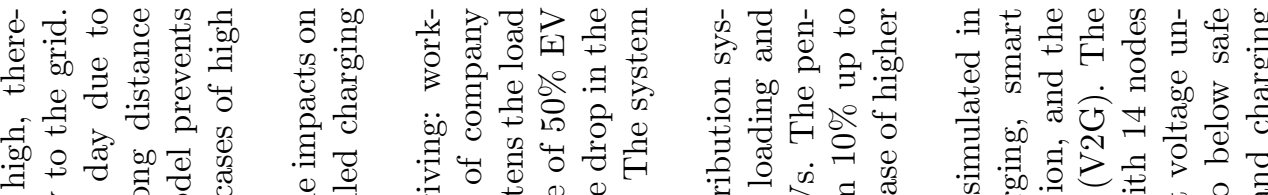

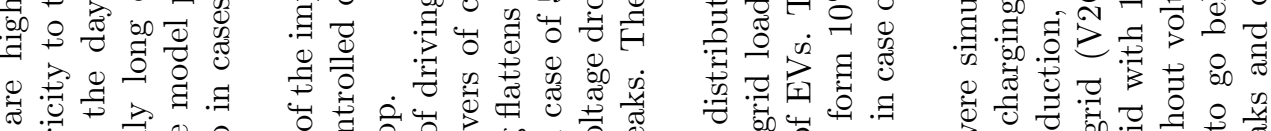

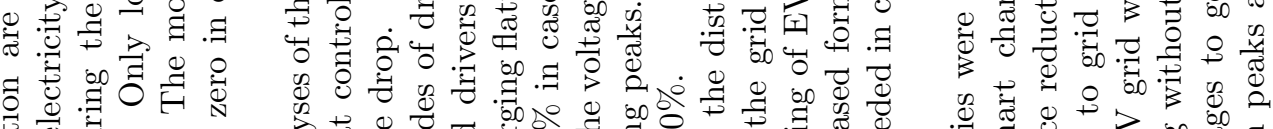

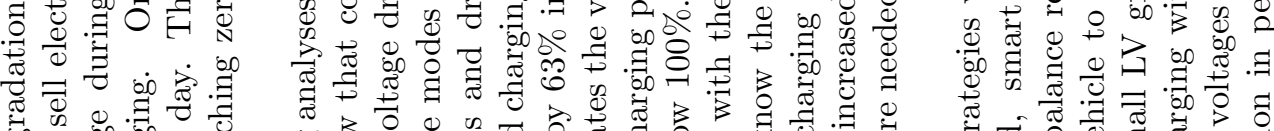
垩

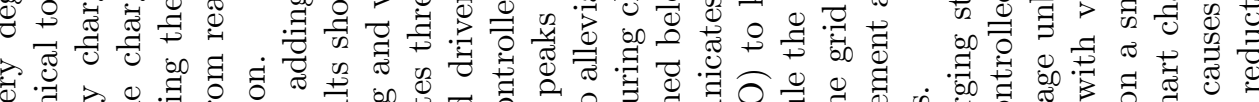

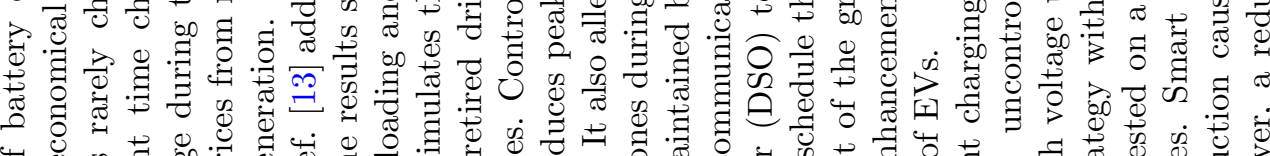

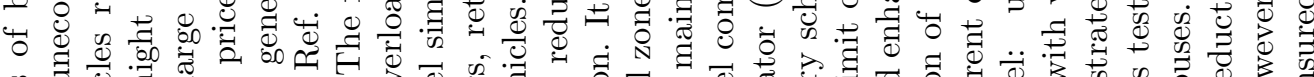

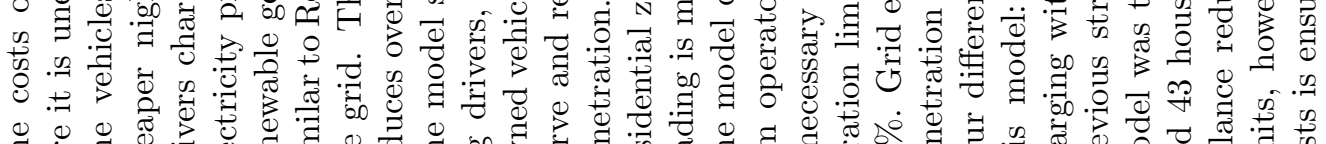

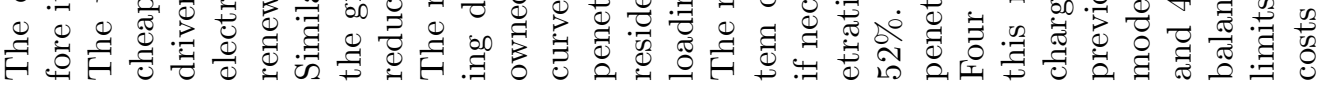

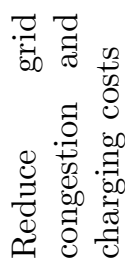

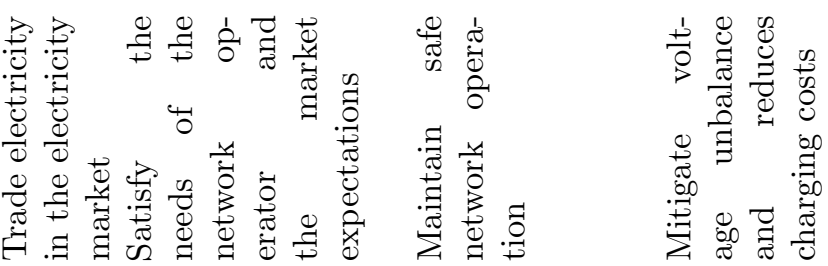

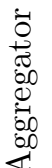

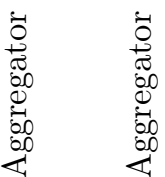

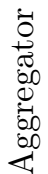

ఫ్ష

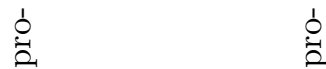

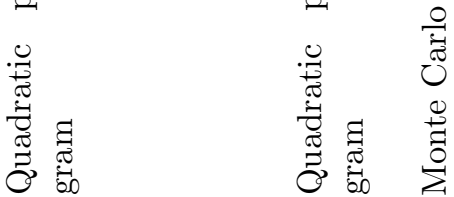

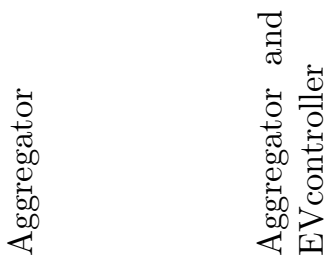

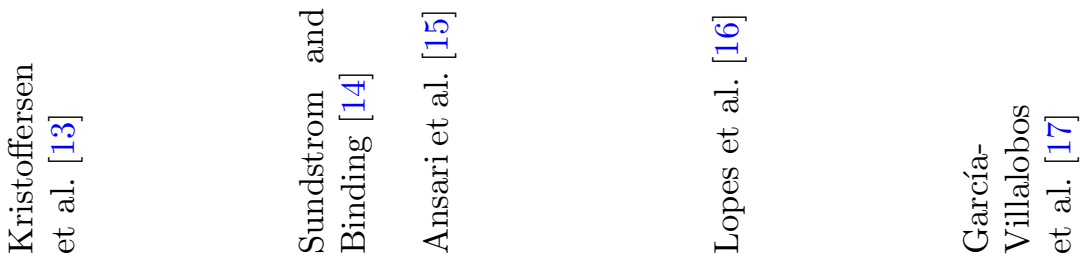

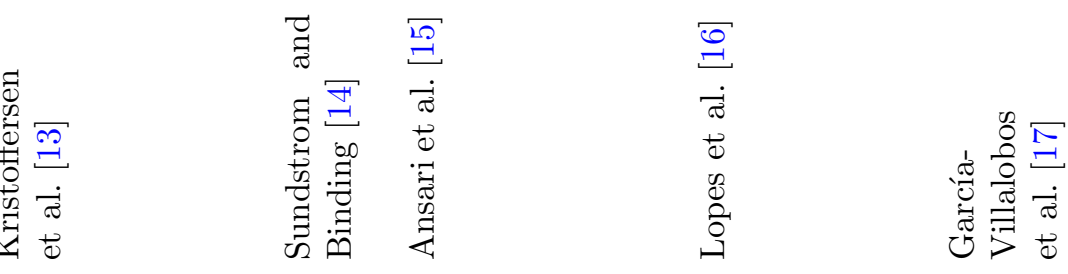

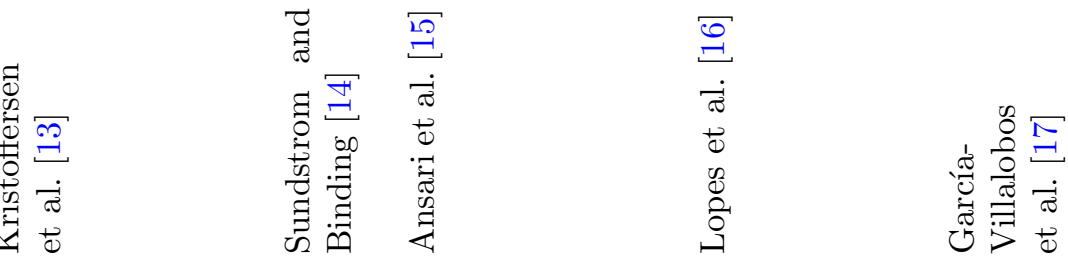

寻 突

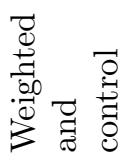




\section{References}

[1] Ma Z, Callaway D, Hiskens I. Decentralized charging control for large populations of plug-in electric vehicles. In: 49th IEEE conf on decis and control (CDC). 2010, p. 206-12.

[2] Ma Z, Callaway D, Hiskens I. Decentralized charging control of large populations of plug-in electric vehicles. IEEE Trans on Control Syst Tech 2013;21(1):67-78.

[3] Zhu Z, Lambotharan S, Chin WH, Fan Z. A mean field game theoretic approach to electric vehicles charging. IEEE Access 2016;4:3501-10.

[4] Kim JD, Rahimi M. Future energy loads for a large-scale adoption of electric vehicles in the city of Los Angeles: Impacts on greenhouse gas (GHG) emissions. Energy Policy 2014;73:620-30.

[5] Rotering N, Ilic M. Optimal charge control of plug-in hybrid electric vehicles in deregulated electricity markets. IEEE Trans on power Syst 2011;26(3):1021-9.

[6] Paevere P, Higgins A, Ren Z, Horn M, Grozev G, McNamara C. Spatio-temporal modelling of electric vehicle charging demand and impacts on peak household electrical load. Sustain sci 2014;9(1):61-76.

[7] Falahati S, Taher SA, Shahidehpour M. Grid frequency control with electric vehicles by using of an optimized fuzzy controller. Appl Energy 2016;178:918-28.

[8] Falahati S, Taher SA, Shahidehpour M. A new smart charging method for EVs for frequency control of smart grid. Int J of Electr Power \& Energy Syst 2016;83:458-69.

[9] Kim J, Son SY, Lee JM, Ha HT. Scheduling and performance analysis under a stochastic model for electric vehicle charging stations. Omega 2017;66, Part B:278 -89.

[10] O'Connell A, Flynn D, Keane A. Rolling multi-period optimization to control electric vehicle charging in distribution networks. IEEE Trans on power Syst 2014;29(1):340-8.

[11] Kara EC, Macdonald JS, Black D, Bérges M, Hug G, Kiliccote S. Estimating the benefits of electric vehicle smart charging at non-residential locations: A data-driven approach. Appl Energy 2015;155:515-25.

[12] Esmaili M, Rajabi M. Optimal charging of plug-in electric vehicles observing power grid constraints. IET Gener, Transm \& Distribution 2014;8(4):583-90.

13] Kristoffersen TK, Capion K, Meibom P. Optimal charging of electric drive vehicles in a market environment. Appl Energy 2011;88(5):1940-8.

[14] Sundstrom O, Binding C. Flexible charging optimization for electric vehicles considering distribution grid constraints. IEEE Trans on Smart Grid 2012;3(1):26-37.

[15] Ansari M, Al-Awami AT, Abido MA, Sortomme E. Optimal charging strategies for unidirectional vehicle-to-grid using fuzzy uncertainties. In: 2014 IEEE PES T\&D Conf and Expo. 2014, p. 1-5.

[16] Lopes JAP, Soares FJ, Almeida PMR. Integration of electric vehicles in the electric power system. Proc of the IEEE 2011;99(1):168-83.

[17] García-Villalobos J, Zamora I, Knezović K, Marinelli M. Multi-objective optimization control of plug-in electric vehicles in low voltage distribution networks. Appl Energy 2016;180:155-68. 


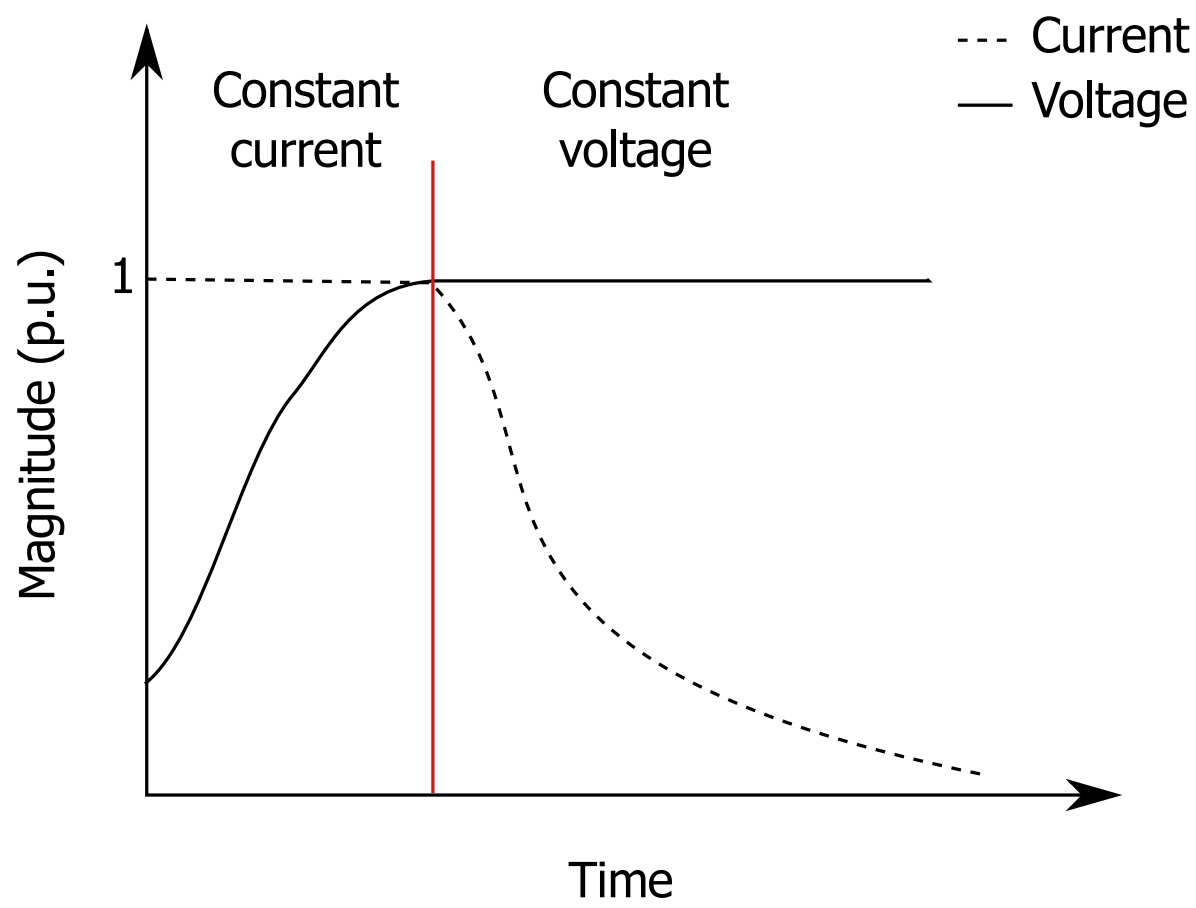

Figure 1: The voltage and current variation during a charging session of a battery. In this diagram the CC-CV method is used for battery charging. This figure is inspired by Ref. [1-3].

\section{References}

[1] Kuperman A, Levy U, Goren J, Zafranski A, Savernin A, Peled I. Modeling and control of a 50KW electric vehicle fast charger. In: 2010 IEEE 26th Conv. of Electr. and Electron. Eng. in Isr. (IEEEI). 2010, p. 000188-9.

[2] Yong JY, Ramachandaramurthy VK, Tan KM, Mithulananthan N. A review on the state-of-the-art technologies of electric vehicle, its impacts and prospects. Renew and Sustain Energy Rev 2015;49:365-85.

[3] Haidar AMA, Muttaqi KM. Behavioral characterization of electric vehicle charging loads in a distribution power grid through modeling of battery chargers. In: 2014 IEEE Ind. Appl. Soc. Annu. Meet. 2014, p. 1-8. 